\title{
Nanobody interaction unveils structure, dynamics and proteotoxicity of the Finnish-type amyloidogenic gelsolin variant
}

\author{
Toni Giorgino $^{\mathrm{a}, \mathrm{b}}$, Davide Mattioni ${ }^{\mathrm{a}, \mathrm{c}, 1}$, Amal Hassan ${ }^{\mathrm{b}, 1}$, Mario Milani ${ }^{\mathrm{a}, \mathrm{b}}$, Eloise Mastrangelo ${ }^{\mathrm{a}, \mathrm{b}}$, \\ Alberto Barbiroli ${ }^{\mathrm{d}}$, Adriaan Verhelle ${ }^{\mathrm{e}}$, Jan Gettemans ${ }^{\mathrm{f}}$, Maria Monica Barzago ${ }^{\mathrm{c}}$, Luisa Diomede ${ }^{\mathrm{c}}$, \\ Matteo de Rosa ${ }^{\mathrm{a}, \mathrm{b}, *}$ \\ a Istituto di Biofisica, Consiglio Nazionale delle Ricerche, Milano, Italy \\ b Dipartimento di Bioscienze, Università degli Studi di Milano, Milano, Italy \\ ${ }^{\mathrm{c}}$ Department of Molecular Biochemistry and Pharmacology, Istituto di Ricerche Farmacologiche Mario Negri IRCCS, 20156 Milan, Italy \\ ${ }^{\mathrm{d}}$ Dipartimento di Scienze per gli Alimenti, la Nutrizione e l'Ambiente, Università degli Studi di Milano, Milano, Italy \\ e Department of Molecular Medicine, Department of Molecular and Cellular Neuroscience, Dorris Neuroscience Center, The Scripps Research Institute, La Jolla, CA 92037, \\ USA \\ ${ }_{\mathrm{f}}^{\mathrm{f}}$ Nanobody Lab, Department of Biochemistry, Faculty of Medicine and Health Sciences, Ghent University, Ghent, Belgium
}

\section{A R T I C L E I N F O}

\section{Keywords:}

Familial amyloidosis Finnish-type

Gelsolin

Nanobody

Caenorhabditis elegans

Molecular dynamics

Pharmacoperone

\begin{abstract}
A B S T R A C T
AGel amyloidosis, formerly known as familial amyloidosis of the Finnish-type, is caused by pathological aggregation of proteolytic fragments of plasma gelsolin. So far, four mutations in the gelsolin gene have been reported as responsible for the disease. Although D187N is the first identified variant and the best characterized, its structure has been hitherto elusive. Exploiting a recently-developed nanobody targeting gelsolin, we were able to stabilize the G2 domain of the D187N protein and obtained, for the first time, its high-resolution crystal structure. In the nanobody-stabilized conformation, the main effect of the D187N substitution is the impairment of the calcium binding capability, leading to a destabilization of the C-terminal tail of G2. However, molecular dynamics simulations show that in the absence of the nanobody, D187N-mutated G2 further misfolds, ultimately exposing its hydrophobic core and the furin cleavage site. The nanobody's protective effect is based on the enhancement of the thermodynamic stability of different G2 mutants (D187N, G167R and N184K). In particular, the nanobody reduces the flexibility of dynamic stretches, and most notably decreases the conformational entropy of the C-terminal tail, otherwise stabilized by the presence of the $\mathrm{Ca}^{2+}$ ion. A Caenorhabditis elegans-based assay was also applied to quantify the proteotoxic potential of the mutants and determine whether nanobody stabilization translates into a biologically relevant effect. Successful protection from G2 toxicity in vivo points to the use of $C$. elegans as a tool for investigating the mechanisms underlying AGel amyloidosis and rapidly screen new therapeutics.
\end{abstract}

\section{Introduction}

AGel amyloidosis (AGel) is a neglected disease caused by deposition of gelsolin (GSN) amyloids and described for the first time in Finland in 1969 [1]. For a long time, AGel has been associated with the substitution of a single residue of the protein, D187 in the protein second domain (G2) (Fig. 1), to either N or Y [2,3]. It has also been considered an endemic pathology in Finland and named Familial Amyloidosis, Finnish-type (FAF). Nowadays, AGel is the preferred name for this disease [4], as new cases have been gradually reported from many other countries demonstrating its worldwide occurrence.
In the last five years, the broader clinical use of genetic tests and the raised awareness of this class of diseases led to the identification of three new AGel forms. A new classification of the disease into three different types, according to the GSN sequence and the organ(s) involved in amyloid deposition, has been therefore proposed and includes: i) a systemic form, caused by D187N and D187Y mutations, respectively known as the Finnish- and Danish-variant; ii) a kidney localized form, associated with the deposition of GSN, either full-length or as fragments, carrying N184K or G167R mutation [5-7]; and iii) a sporadic form, caused by wild-type (WT) GSN deposits surrounding a sellar glioma of the hypophysis [8]. All AGel types share the lack of

\footnotetext{
* Corresponding author at: Istituto di Biofisica CNR, \% Dip di Bioscienze, via Celoria 26, 20133 Milano, Italy.

E-mail address: matteo.derosa@cnr.it (M. de Rosa).

${ }^{1}$ These authors contributed equally to this work.
} 


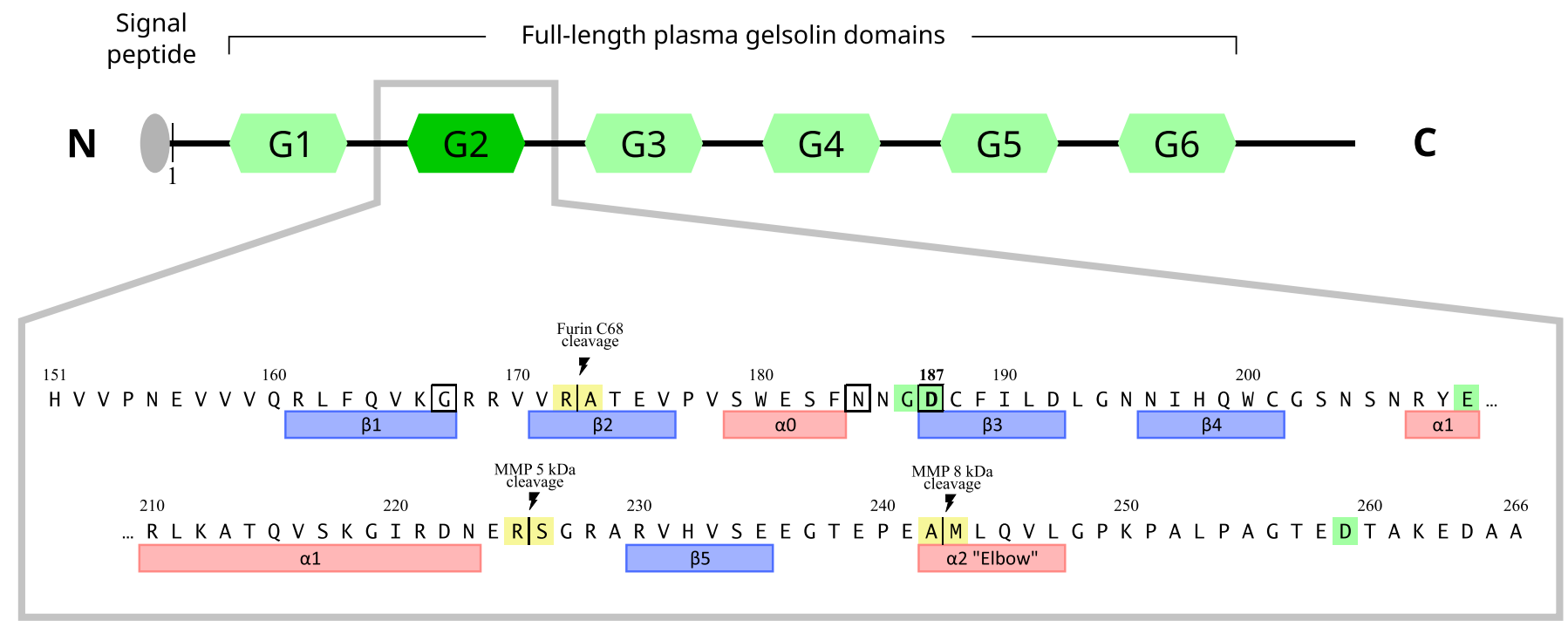

Fig. 1. Domain architecture of plasma gelsolin and sequence of the G2 domain. The G2 construct comprises residues 151 to 266 around the second domain of fulllength plasma gelsolin (residue numbering excludes the signal peptide). Secondary structure elements ( $\alpha 0$ to $\alpha 2, \beta 1$ to $\beta 5$ ) are indicated below the sequence; calciumcoordinating residues are marked in green, and known amyloidosis-causing amino-acid mutations (D187N object of this study, as well as D187Y, G167R, N184K) are boxed. Vertical bars indicate the locations of aberrant processing by furin and matrix metallo-proteases (MMP), ultimately leading to fibril formation and AGel.

effective pharmacological therapies that cure the disease targeting the source of toxicity, rather than acting only as palliative, symptomatic treatments.

Among the listed GSN variants, the D187N protein is the best biochemically and biophysically characterized. $>20$ years of in vitro and in vivo studies led to a consensus on the pathological mechanism underlying Finnish AGel type, although this model has been questioned by recent findings [9]. According to this model, aspartic acid 187 is part of a cluster of residues in the G2 domain of GSN, able to chelate a calcium ion [10]. Its $\mathrm{N}$ or Y substitution compromises calcium binding [11-14], leading to the exposure of an otherwise buried sequence, which is recognized by the furin protease [15]. In the Golgi, this intracellular enzyme cleaves GSN producing a C-terminal $68 \mathrm{kDa}$ fragment (C68). C68 is later exported to the extracellular space where it is further processed by matrix metalloproteases, eventually producing 5 and $8 \mathrm{kDa}$ highly amyloidogenic peptides [16]. These fragments rapidly aggregate and deposit in different tissues and organs [17,18]. In stark contrast to the extensive biochemical knowledge available on the D187N mutant, its crystal structure has never been obtained, limiting the mechanistic understanding of GSN instability and aberrant proteolysis.

This study aims at characterizing the crystal structure of the isolated $\mathrm{G} 2$ domain (Fig. 1) of the D187N protein $\left(\mathrm{D} 187 \mathrm{~N}_{\mathrm{G} 2}\right.$ ) by exploiting a recently-developed nanobody (Nb) targeting GSN [19]. Different Nbs able to bind mutated GSN and to detect or prevent its aggregation, have been developed and tested [19-22]. Among them, Nb11 proved to be the most efficient one. Studies performed in vitro and in vivo demonstrated that Nb11 binds G2 domain of GSN with high affinity, irrespective of calcium, and protects the mutated domain from furin proteolysis, thus skipping the first event of the aberrant proteolytic cascade (19-22). Inspired by the recent use of $\mathrm{Nbs}$ as a unique tool for structural biological studies [23], we employed Nb11 to increase the stability of

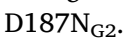

The successful co-crystallization of $\mathrm{D} 187 \mathrm{~N}_{\mathrm{G} 2}$ in complex with $\mathrm{Nb} 11$ $\left(\mathrm{D} 187 \mathrm{~N}_{\mathrm{G} 2}: \mathrm{Nb} 11\right)$ showed that the nanobody protects $\mathrm{D} 187 \mathrm{~N}_{\mathrm{G} 2}$ from furin-induced proteolysis, stabilizing the G2 C-terminal linker. Such stabilization is achieved allosterically since the Nb11 binding site locates far from the furin cleavage site. We complemented the structural results cross-referencing molecular dynamics (MD) simulations insights with thermal denaturation studies and furin proteolysis assays. These studies were extended to other mutations causing AGel, such as G167R and N184K.

In the absence of cellular or animal models recapitulating G167R and N184K-related AGel as well as the toxicity of the WT or mutated G2 domains, we decided to employ the invertebrate nematode Caenorhabditis elegans as "biosensor", able to recognize proteins which exert in vivo a biologically relevant effect [24-27]. This approach takes advantage of the ability of the pharynx of worms, fundamental for their feeding and survival, to be inhibited when it meets molecules acting as chemical stressors [28]. This nematode-based method has been widely applied to recognize the toxicity of different amyloidogenic proteins in vivo, demonstrating that singular molecular mechanisms underlie their proteotoxic activity [24-27,29]. The protein folding, oligomerization propensity and the exposure of hydrophobic residues on the outside of the protein are relevant for the toxic action of $\beta$-amyloid $(\mathrm{A} \beta)$ and HIVmatrix protein p17 [25,27,29]. Instead, amyloidogenic cardiotoxic light chains are recognized as stressors by $C$. elegans thanks to their ability to interact with metal ions and continuously generate reactive oxygen species [24,26].

Our findings indicate that $C$. elegans efficiently recognizes the proteotoxic potential of the G2 domains and can discriminate between different level of toxicity. Furthermore, the stabilizing effects induced by Nb11 on G2 translated into an effective protection in vivo. These observations point to the use of this nematode-based model as a valuable tool for investigating the mechanisms underlying AGel.

\section{Materials and methods}

\subsection{Protein production}

If not otherwise stated, all chemicals are from Sigma-Aldrich (Merck Millipore Ltd., Tullagreen, Carrigtwohill, Co. Cork, IRL) and of the best available purity. All preparative and analytic chromatographies were performed on a ÄKTA pure 25 system (GE Healthcare, Uppsala, Sweden) using prepacked columns from the same company.

\subsubsection{Gelsolin expression and purification}

Constructs and expression conditions for GSN variants as isolated G2 domain or full-length proteins were performed as already reported [30,31]. The here named G2 refers to the shorter G2s construct in [30] 
Table 1

Data collection and refinement statistics. Notes: Values in parentheses refer to the highest resolution shell. ${ }^{*} \mathrm{R}_{\text {work }}=\Sigma \mathrm{hkl}|| \mathrm{Fo}|-| \mathrm{Fc}|| / \Sigma \mathrm{hkl}|\mathrm{Fo}|$ for all data, except $10 \%$, which were used for $\mathrm{R}_{\text {free }}$ calculation. ${ }^{\S}$ Average temperature factors over the whole structure.

\begin{tabular}{|c|c|c|}
\hline & Orthorhombic & Tetragonal \\
\hline PDB ID & $6 \mathrm{H} 1 \mathrm{~F}$ & - \\
\hline \multicolumn{3}{|l|}{ Data collection } \\
\hline Space group & $\mathrm{P} 22_{1} 2_{1} 2_{1}$ & $\mathrm{P} 4_{1} 2_{1} 2$ \\
\hline Cell dimension: a, b, c $(\AA)$ & $33.8,46.8,132.1$ & $77.0,77.0,88.8$ \\
\hline Unique reflections & 17,289 & 10,995 \\
\hline \multirow[t]{2}{*}{ Resolution range $(\AA)$} & $46.8-1.9$ & $46.4-2.4$ \\
\hline & $(1.94-1.90)$ & $(2.49-2.40)$ \\
\hline $\mathrm{CC}_{1 / 2}$ & $0.990(0.714)$ & $0.999(0.800)$ \\
\hline Completeness (\%) & $99.8(99.9)$ & $100(100)$ \\
\hline Multiplicity & 5.1 & 16.9 \\
\hline \multicolumn{3}{|l|}{ Refinement } \\
\hline Resolution range $(\AA)$ & $44.1-1.9$ & $46.4-2.4$ \\
\hline $\mathrm{R}_{\text {work }} / \mathrm{R}_{\text {free }}(\%)^{*}$ & $19.9 / 23.3$ & $18.6 / 26.0$ \\
\hline \multicolumn{3}{|l|}{ RMSD } \\
\hline Bonds (Å) & 0.006 & 0.008 \\
\hline Angles $\left({ }^{\circ}\right)$ & 0.786 & 0.964 \\
\hline \multicolumn{3}{|l|}{ Ramachandran plot } \\
\hline In preferred regions (\%) & 96.0 & 95.7 \\
\hline Outliers (\%) & 0.0 & 0.4 \\
\hline B-factors $\left(\AA^{2}\right)^{\S}$ & 30 & 66 \\
\hline
\end{tabular}

and spans residues 151-266 of the GSN, according to the mature plasma isoform (Fig. 1). Purification followed the protocol previously described [30]. $\Delta \mathrm{G} 2$ construct for the expression of $\mathrm{WT}_{\Delta \mathrm{G} 2}$ harbours a WT sequence but lacks the first beta-strand $(\beta 1)$; it spans residues $168-266$ and it is purified following the same protocol developed for the other G2 domains [31]. Briefly, G2 domains were passed through a Ni-chelating column (HisTrap) and gel filtered in a Superdex 75 following the removal of the His-tag. Full-length proteins went through three chromatographic steps without cleaving the N-terminal tag, $\mathrm{Hi}$ sTrap, MonoQ and gel filtration on a Superdex 200. G2 domains were stored in a $20 \mathrm{mM}$ HEPES solution, $\mathrm{pH} 7.4$, containing $100 \mathrm{mM} \mathrm{NaCl}$ and $1 \mathrm{mM} \mathrm{CaCl}_{2}$ whereas full-length GSN in $20 \mathrm{mM}$ HEPES solution, $\mathrm{pH} 7.4$, containing $100 \mathrm{mM} \mathrm{NaCl}, 1 \mathrm{mM}$ EDTA and $1 \mathrm{mM}$ EGTA. Whenever required proteins were concentrated or buffer-exchanged in centrifugal filters Amicon ${ }^{\circledR}$ Ultra (Merck Millipore Ltd., Tullagreen, Carrigtwohill, Co. Cork, IRL) with cutoffs of either $10 \mathrm{k}$ or $30 \mathrm{k}$.

\subsubsection{Nb11 expression and purification}

The synthetic gene coding for Nb11 [19] fused to the thrombin cleavage site and $6 \mathrm{xHis}$ tag at the C-terminus was purchased by Eurofins genomics (Ebersberg, Germany). The sequence was optimized for $E$. coli codon usage and the gene cloned in a pET11 vector (Merck Millipore Ltd., Tullagreen, Carrigtwohill, Co. Cork, IRL). Tagged Nb11 was produced in SHuffle ${ }^{\circledR}$ T7 E. coli cells (New England BioLabs Inc., Ipswich, USA) grown in LB medium. Once OD at $600 \mathrm{~nm}$ reached the value of 0.6 , the expression of the gene was induced with $0.5 \mathrm{mM}$ Isopropyl $\beta$ D-1-thiogalactopyranoside and cells harvested by centrifugation $16 \mathrm{~h}$ after incubation at $20{ }^{\circ} \mathrm{C}$. Cells were resuspended in $20 \mathrm{mM} \mathrm{Na}_{2} \mathrm{PO}_{4}$, $\mathrm{pH} 7.4$, containing $500 \mathrm{mM} \mathrm{NaCl}$ (supplemented with DNase I and cOmplete $^{\mathrm{TM}}$ Protease Inhibitor Cocktail), lysed with a Basic Z Bench-top cell disruptor (Constant system Ltd., UK) operating at $25 \mathrm{kPsi}$ and centrifuged at 38,000 RCF. The clarified crude extract was loaded on a $5 \mathrm{ml}$ HisTrap and Nb11 eluted stepwise with the lysis buffer supplemented with $500 \mathrm{mM}$ imidazole. Fractions enriched in $\mathrm{Nb} 11$ were passed through a Superdex 75, equilibrated with 20 mM HEPES, $\mathrm{pH} 7.4$, $100 \mathrm{mM} \mathrm{NaCl}$.

\subsection{Crystallization, structure solution and analysis}

\subsubsection{Crystallization}

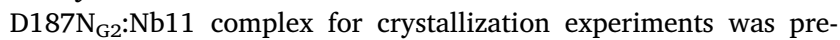
pared by mixing equimolar amounts of the individual protein. The complex was loaded on a Superdex 75 increase (equilibrated with $20 \mathrm{mM}$ HEPES, $100 \mathrm{mM} \mathrm{NaCl}, 1 \mathrm{mM} \mathrm{CaCl}_{2}$, pH 7.4), obtaining a single peak, consistent with the theoretical molecular weight of the complex, which was concentrated to $12 \mathrm{mg} / \mathrm{ml}$ in the same buffer. This sample was used for extensive crystallization screening using an Oryx-8 crystallization robot (Douglas Instruments Ltd., UK) and several commercial solutions in a sitting-drop set up. The purified complex $(0.15 / 0.25 \mu \mathrm{l})$ was mixed with $0.25 / 0.15 \mu$ of the reservoir solutions. Two different conditions yielded crystals after 2-6 days at $20^{\circ} \mathrm{C}$, namely (i) $0.1 \mathrm{M}$ potassium thiocyanate, $30 \%$ poly(ethylene glycol) methyl ether 2000 and $4.0 \mathrm{M}$ sodium formate and (ii) $0.1 \mathrm{M}$ potassium phosphate, $\mathrm{pH} 6.2$, $10 \%(\mathrm{v} / \mathrm{v})$ glycerol and $25 \%(\mathrm{v} / \mathrm{v}) 1,2$ propanediol. Crystals were soaked with the respective reservoir solution supplemented with $20 \%$ glycerol, flash-frozen in liquid $\mathrm{N}_{2}$ and diffraction data were collected at beamline ID23-1 (European Synchrotron Radiation Facility, Grenoble, France).

\subsubsection{Data processing, structure solution, refinement and analysis}

The two datasets (orthorhombic and tetragonal crystals grown in condition (i) and (ii), respectively) were processed with XDS [32], scaled with Aimless [33], and the structures solved by molecular replacement using the program phaser [34] and the PDB: 4 S10 as the searching model. The orthorhombic structure $(1.9 \AA)$ was refined with phenix.refine [35] and manual model building was performed with COOT [36]. The final coordinates were deposited in the RCSB database with accession code PDB: $6 \mathrm{H} 1 \mathrm{~F}$. The tetragonal structure $(2.4 \AA)$ could be refined only partially due to the poor quality of the diffraction (see Table 1 for the complete data collection and refinement statistics). The structural analysis was performed using the orthorhombic structure, except where indicated; all of the figures were prepared with either PyMOL or VMD [37,38].

All the other structures used for the B factor analysis were subjected to 3 cycles of refinement with phenix.refine. $\mathrm{B}$ factors for the $\mathrm{WT}_{\mathrm{G} 2}$ : $\mathrm{Nb} 11$ and $\mathrm{D} 187 \mathrm{~N}_{\mathrm{G} 2}: \mathrm{Nb} 11$ were averaged between asymmetric molecules or between datasets, respectively. The rest of the analysis was performed as reported earlier [39].

\subsection{Molecular dynamics (MD) simulations}

The crystal structure of G2 domain in complex with Nb11 (PDB: 4S10) was used to build the initial configuration for MD runs. The structure editing and building facilities provided by the HTMD software package [40] were used to construct a set of systems by selecting either the G2 domain only (chain D of the original PDB file) or the domain together with the bound $\mathrm{Nb} 11$ (chains D and B). In silico mutations were applied to restore residues 226 and 228 to their WT amino acids, to generate the $\mathrm{D} 187 \mathrm{~N}$ and $\mathrm{N} 184 \mathrm{~K}$ systems, and to remove the coordinated $\mathrm{Ca}^{2+}$ ion where appropriate. The titratable side chains and initial $\mathrm{H}$ bond network were then optimized at $\mathrm{pH} 6.5$ via the proteinPrepare procedure of HTMD [41]; systems were solvated with transferable intermolecular potential with 3 points (TIP3P) water at $100 \mathrm{mM}$ $\mathrm{NaCl}$ ionic strength and parameterized with the CHARMM36 force field [42]. The systems thus prepared were minimized and equilibrated for $4 \mathrm{~ns}$ in constant pressure conditions at $1 \mathrm{~atm}$, yielding orthorhombic boxes with a water buffer of at least $15 \AA$ per side. All simulations were conducted via the ACEMD software with a timestep of $4 \mathrm{fs}$, particlemesh Ewalds long-range electrostatics treatment and the hydrogen mass repartitioning scheme [43].

Each system was set for a production run in the number volume temperature (NVT) ensemble. Simulations of the G2 system without Nb11 were completely unrestrained and therefore the globular domain 
was free to diffuse in the solvent. To obtain a more efficient simulation box for the G2:Nb11 elongated complex while still preventing self-interactions with periodic images, its rotational diffusion was restricted by restraining $\mathrm{C} \alpha$ atoms of the Nb11's secondary structure elements with a harmonic force of $0.025 \mathrm{kcal} / \mathrm{mol} / \AA^{2}$. No restraint was applied to the G2 domain, nor to the contact region of Nb11. Runs were interrupted at $800 \mathrm{~ns}$ or when the full solvation of the C-terminus caused its extension outside of the simulation box. The $\mathrm{WT}_{\mathrm{G} 2}: \mathrm{Nb} 11$ simulation was also truncated at $750 \mathrm{~ns}$ because the complex became transiently unbound. Local conformational flexibility was assessed computing the root-mean-square fluctuation (RMSF) of backbone atoms, aggregated by residue; values are reported as the equivalent $\mathrm{B}$ factors according to the equation $\mathrm{B}=8 \pi^{2} / 3 \mathrm{RMSF}^{2}$.

\subsection{Thermal stability}

\subsubsection{Circular dichroism (CD) spectroscopy}

CD measurements were performed with a J-810 spectropolarimeter (JASCO Corp., Tokyo, Japan) equipped with a Peltier system for temperature control. All measurements were performed on $15 \mu \mathrm{MG} 2$, $\mathrm{Nb} 11$, or the complex in $20 \mathrm{mM}$ HEPES solution containing $100 \mathrm{mM}$ $\mathrm{NaCl}$ and $1 \mathrm{mM} \mathrm{CaCl}{ }_{2}$ at $\mathrm{pH}$ 7.4. Temperature ramps were recorded from $10{ }^{\circ} \mathrm{C}$ to $95^{\circ} \mathrm{C}$ (temperature slope $50^{\circ} \mathrm{C} / \mathrm{h}$ ) in a $0.1 \mathrm{~cm}$ path length cuvette and monitored at $218 \mathrm{~nm}$ wavelength.

\subsubsection{Thermofluor}

Thermodynamic stabilities were also evaluated in the presence of Sypro Orange, a fluorogenic probe unspecifically binding hydrophobic surfaces and with excitation/emission spectra compatible with standard qPCR machines. WT and mutated G2 domains with or without equimolar Nb11, were diluted to $1 \mathrm{mg} / \mathrm{ml}$ in $20 \mathrm{mM}$ HEPES solution containing $100 \mathrm{mM} \mathrm{NaCl}$ and $1 \mathrm{mM} \mathrm{CaCl}_{2}, \mathrm{pH}$ 7.4. Each solution was mixed with $3 \mu \mathrm{l}$ of a 1/500 (v/v) dilution of Sypro Orange, in a total volume of $20 \mu$ l. Fifteen $\mu \mathrm{l}$ of each sample were transferred to multiplate ${ }^{\circledR}$ PCR Plates, sealed with Microseal ${ }^{\circledR}$ 'B' Film, and analyzed in triplicate in an MJ Mini ${ }^{\mathrm{TM}}$ Thermal Cycler (hardware and consumables from Bio-Rad Laboratories Inc., Hercules, USA). The temperature was increased from $10{ }^{\circ} \mathrm{C}$ to $100{ }^{\circ} \mathrm{C}$ in $0.2{ }^{\circ} \mathrm{C}$ steps with $10 \mathrm{~s}$ equilibration before each measurement. Fluorescence intensity was measured within the excitation and emission wavelength ranges of 470-505 and 540-700 nm, respectively. $T_{m}$ was calculated as the minimum of the first-derivative of the traces using the manufacturer software and the value is reported as the average of triplicate measures.

\subsection{Furin assay}

Furin cleavage assays were performed in a total volume of $30 \mu \mathrm{l}$, using $1 \mathrm{U}$ of commercial furin enzyme (New England BioLabs Inc., Ipswich, Massachusetts, USA) and $1 \mathrm{mg} / \mathrm{ml}$ of full-length WT and mutated GSN in $20 \mathrm{mM}$ 2-(N-morpholino)ethanesulfonic acid, pH6.5, containing $100 \mathrm{mM} \mathrm{NaCl}$ and $1 \mathrm{mM} \mathrm{CaCl}_{2}$ in the presence or absence of $1 \mathrm{mg} / \mathrm{ml}$ of Nb11 (roughly 1:6 GSN:Nb11 molar ratio). To monitor the susceptibility to proteolysis, $12 \mu \mathrm{l}$ aliquots of the reaction mix were collected right upon addition of furin and $3 \mathrm{~h}$ after incubation at $37^{\circ} \mathrm{C}$. The reaction was blocked by adding to each sample $4 \mu \mathrm{l}$ of Sodium Dodecyl Sulphate (SDS) loading buffer $4 \times$ (BioIO-RadAD Laboratories Inc., Hercules, USA) supplemented with $0.7 \mathrm{M} \beta$-mercaptoethanol and by incubation at $90^{\circ} \mathrm{C}$ for $3 \mathrm{~min}$. Proteolysis reaction was monitored by SDS - PolyAcrylamide Gel Electrophoresis using ExpressPlus ${ }^{\mathrm{TM}}$ PAGE $(12 \%)$ and the provided running buffer (GenScript Biotech Corp., USA).

\subsection{Proteotoxicity studies on C. elegans}

Bristol N2 strain was obtained from the Caenorhabditis elegans Genetic Center (CGC, University of Minnesota, Minneapolis, MN, USA) and propagated at $20^{\circ} \mathrm{C}$ on solid Nematode Growth Medium (NGM) seeded with E. coli OP50 (CGC) for food. The effect of G2 domains on pharyngeal behavior was evaluated as already described [27]. Briefly, worms were incubated with $1-1000 \mu \mathrm{g} / \mathrm{ml}$ of G2 domains (100 worms/ $100 \mu \mathrm{l})$ in $2 \mathrm{mM}$ HEPES solution containing $1 \mathrm{mM} \mathrm{NaCl}$ and $0.1 \mathrm{mM}$ $\mathrm{CaCl}_{2}$, pH 7.4. Equimolar concentrations of $\mathrm{WT}_{\mathrm{G} 2}$ or $\mathrm{WT}_{\Delta \mathrm{G} 2}(18 \mu \mathrm{M}$, corresponding to $250 \mu \mathrm{g} / \mathrm{ml}$ of WTG2) were administered to worms in the same conditions. Hydrogen peroxide $(1 \mathrm{mM})$ was administered in dark conditions as a positive control. After $2 \mathrm{~h}$ of incubation on orbital shaking, worms were transferred onto NGM plates seeded with OP50 E. coli. The pharyngeal pumping rate, measured by counting the number of times the terminal bulb of the pharynx contracted over a 1-min interval, was scored 2 and $24 \mathrm{~h}$ later. Control worms were fed $2 \mathrm{mM}$ HEPES solution containing $1 \mathrm{mM} \mathrm{NaCl}$ and $0.1 \mathrm{mM} \mathrm{CaCl}_{2}$, pH 7.4 (Vehicle) only. To evaluate the protective effect of Nb11, worms were fed for $2 \mathrm{~h} \mathrm{G} 2$ domains alone $\left(250 \mu \mathrm{g} / \mathrm{ml}\right.$ for $\mathrm{WT}_{\mathrm{G} 2}$ and $\mathrm{D} 187 \mathrm{~N}_{\mathrm{G} 2}$ and

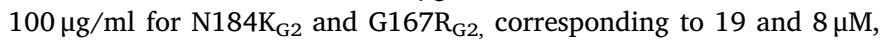
respectively), $8-19 \mu \mathrm{M} \mathrm{Nb} 11$ alone, or G2 domains previously pre-incubated for $10 \mathrm{~min}$ at room temperature under shaking conditions with equimolar concentration of Nb11 to allow the formation of the complex. Nematodes were then transferred to NGM plates seeded with fresh OP50 E. coli and the pumping rate was scored after 2 and $24 \mathrm{~h}$. Worms were also exposed to Vehicle in the same experimental conditions.

\section{Results}

\subsection{Crystal structure of the $D 187 \mathrm{~N}_{\mathrm{G} 2}: \mathrm{Nb} 11$ complex}

Crystals of the isolated $\mathrm{D} 187 \mathrm{~N}_{\mathrm{G} 2}: \mathrm{Nb} 11$ complex readily appeared in different conditions, allowing the collection of two X-ray diffraction datasets of different quality. Particularly, the crystal grown in condition (i) above, belonging to the $\mathrm{P} 2{ }_{1} 2_{1} 2_{1}$ space group, diffracted to $1.9 \AA$ resolution, and the one that appeared in condition (ii), belonging to the $\mathrm{P}_{1} 2_{1} 2$ space group, diffracted to $2.4 \AA$. The resulting models are hereafter referred to as the orthorhombic and tetragonal structure, respectively (Fig. 2); the complete list of the data collection and refinement statistics is reported in Table 1 . Due to the difference in quality of the data, the orthorhombic structure is used to infer the impact of the D187N mutation on the GSN structure (Fig. 2), unless otherwise stated.

Both the structures obtained confirm that Nb11 binds the G2 domain over an extended area including the $\beta 5$-loop- $\alpha 2$ region (residues $230-234,238-245$ ) and the loop- $\beta 4$ stretch (residues 193-198) as already observed for WT gelsolin (PDB: 4S10, [19]). The binding region is opposite from the aberrant cleavage site (residues 168-172), which had previously raised suspicions of a crystallographic artifact. The structures obtained here rule out this hypothesis, since it is unlikely that three different crystal packings $\left(\mathrm{WT}_{\mathrm{G} 2}\right.$ : $\mathrm{Nb} 11$ belongs to $\mathrm{P} 1$ space group) artificially stabilize the same assembly (Fig. 2A). Thus, the 3D structures of G2:Nb11 appear unable to explain how the binding to Nb11 in a distal area could shield G2 from furin proteolysis without additional data.

The second remarkable feature of the $\mathrm{WT}_{\mathrm{G} 2}$ and $\mathrm{D} 187 \mathrm{~N}_{\mathrm{G} 2}$ assemblies is that the G2 structures are almost identical (root mean squared deviation, RMSD, $0.25 \AA$ over 90 C $\alpha$ atoms). Besides, two striking differences were observed: the absence of the coordinated calcium ion, and a shorter stretch of ordered C-terminal segment in $\mathrm{D} 187 \mathrm{~N}_{\mathrm{G} 2}$ (Fig. 2A). In the C-terminus of mutated G2, we could only model up to residue 258 and 255 in the orthorhombic and tetragonal structure, respectively (Fig. 2A), suggesting that the remaining stretch of the protein is highly flexible and invisible to X-rays (the last resolved amino acid in $\mathrm{WT}_{\mathrm{G} 2}$ is 261). The disorder prediction algorithm MobiDB-lite [44] indeed reports a putative disordered region around residues 220-258 owing to its poly-ampholitic character (Supplementary Fig. S1). Besides the C-terminus, all residues are modelled but a few side chains of the Nb11 chain (namely V2, K65 and L128).

The superimposition of the orthorhombic structure of $\mathrm{D} 187 \mathrm{~N}_{\mathrm{G} 2}$ to that of the $\mathrm{WT}_{\mathrm{G} 2}$ (PDB: 1KCQ), shows no major conformational changes 


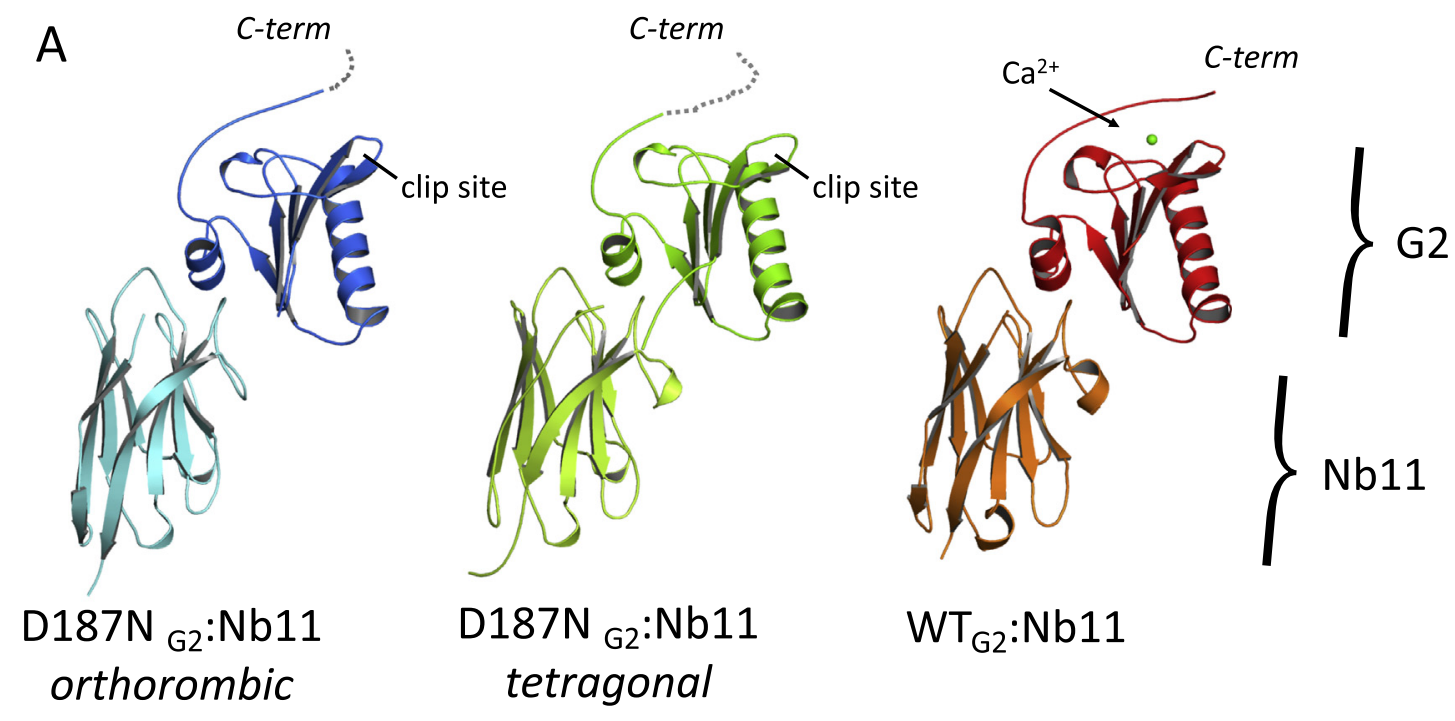

B

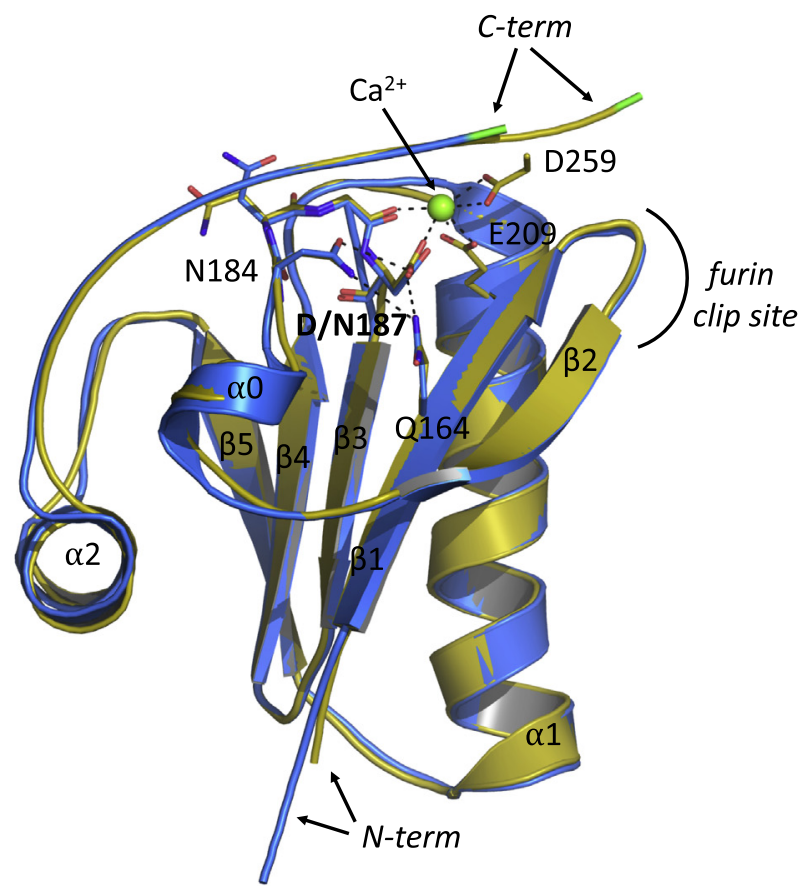

Fig. 2. Crystal Structure of the complexes formed by WT or D187N Gelsolin G2 domains with the Nb11 nanobody. A) The overall structure of the D187N $\mathrm{N}_{\mathrm{G} 2}$ :Nb11 complexes compared to the $\mathrm{WT}_{\mathrm{G} 2}: \mathrm{Nb} 11$. Complexes are represented in cartoon and colored blue/cyan (orthorhombic D187 $\mathrm{N}_{\mathrm{G} 2}: \mathrm{Nb} 11$ ), green/light green (tetragonal $\left.\mathrm{D} 187 \mathrm{~N}_{\mathrm{G} 2}: \mathrm{Nb} 11\right)$ and red/orange (PDB:4S10, $\left.\mathrm{WT}_{\mathrm{G} 2}: \mathrm{Nb} 11\right)$; the calcium ion is shown as a green sphere. The C-terminal residues unresolved in the D187N structures are arbitrarily displayed by a dashed grey line. B) Superimposition of the $\mathrm{D}_{187 \mathrm{~N}_{\mathrm{G} 2} \text { domain extrapolated from the orthorhombic structure with the } \mathrm{WT}} \mathrm{G}_{2}(\mathrm{PDB}: 1 \mathrm{KCQ})$. Residues of the calcium cluster (green sphere) and those found altered in the N184K structure are shown as sticks. WT and D187N variants share high structural similarity (RMSD: $0.25 \AA$ over 90 C $\alpha$ atoms).

(as is the case for the G167R variant) nor the rearrangement of the hydrogen bond network in the core of the domain in the N184K variant, unlike it was observed for the other G2 mutants (Fig. 2B). Residues G186, D187 and E209 of the calcium-coordinating cluster show remarkable conformational conservation (D259, the fourth residue of the cluster, lies in the unresolved C-terminal stretch).

\subsection{Impact of the D187N mutation on the structure of the G2 domain}

A large body of evidence indicates that the presence of D187N mutation mainly affects the ability to bind the calcium ion [11-14]. In $\mathrm{WT}_{\mathrm{G} 2}$ the calcium binding site is a highly polar cavity delimited by the protein core, the side chain of K166 and the C-terminal tail (Fig. 3A, left). The ion is pentacoordinated by the side-chains of residue D187, E209 and D259 and by the main-chain O atom of G186. The site is open to the solvent on the side opposite to K166, where two ordered water molecules are visible in the $\mathrm{WT}_{\mathrm{G} 2}$ structure (Fig. 3A, left).

In the orthorhombic structure of $\mathrm{D} 187 \mathrm{~N}_{\mathrm{G} 2}$, although the overall geometry of the calcium binding is maintained, some differences are visible. The residue D259 could not be modelled and the presence of a water molecule in its place (bound to the $\mathrm{O}$ atom of T257) shows that the residue is extruded from the cavity. Two more water molecules are found overlapping neither with the calcium ion nor with other solvent molecules present in the $\mathrm{WT}_{\mathrm{G} 2}$ structure. The side-chain of $\mathrm{K} 166$ also undergoes small rearrangements: its amino tip becomes more flexible, based on the quality of the electron density, and the interaction with 

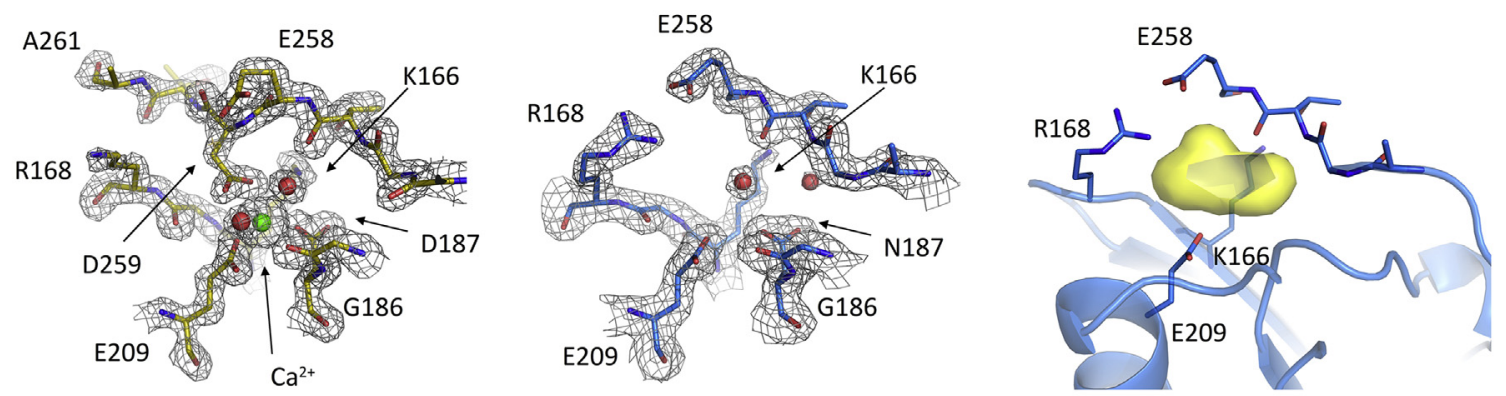

A

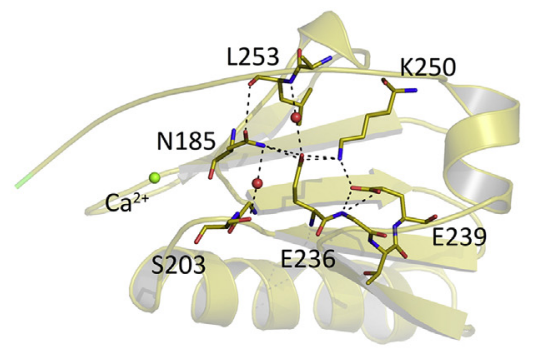

B

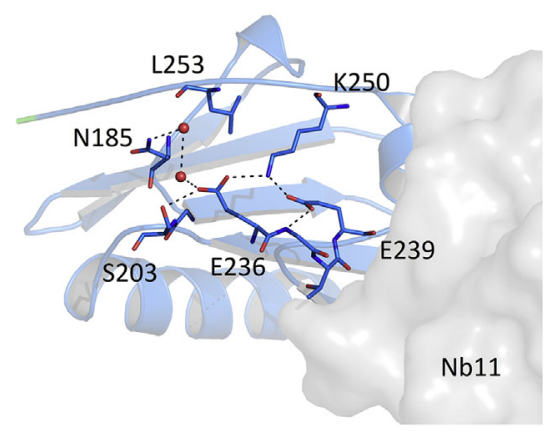

Fig. 3. Impact of the D187N mutation on the structure of the gelsolin G2 domain. A) Details of the calcium binding site in the WT $\mathrm{G}_{\mathrm{G} 2}$ (yellow, PDB: $1 \mathrm{KCQ}$ ) and $\mathrm{D} 187 \mathrm{~N}_{\mathrm{G} 2}$ (blue). Electron density is contoured at 1.5 o. The cavity volume induced by D187N substitution was generated by PyMOL and is shown in yellow. B)

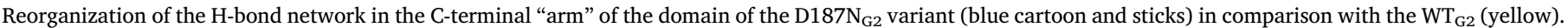
In $1 \mathrm{KCQ}$ cadmium substitutes the physiological ion; here it is labelled as calcium for readability $\left(\mathrm{Ca}^{2+}\right.$, green sphere); ordered water molecules playing a structural role in the respective regions are represented as red spheres.

residues 187 and 259 is either lost or weakened. The N187-K166 distance is $4.6 \AA$, whereas $3.1 \AA$ separate $\mathrm{D} 187$ from $\mathrm{K} 166$ in the $\mathrm{WT}_{\mathrm{G} 2}$ due to a stronger polar interaction (Fig. 3A, middle). This small reorganization of the calcium binding residues, as well as the lack of the coordinated ion, are sufficient to create a small cavity (Fig. 3A, right, computed by PyMOL [37]), a known source of instability in proteins [45]. Even though this cleft is solvent-exposed and accessible, the high concentration of its acidic residues might be the force driving the stretching of both D259 residue and the whole C-terminal tail.

The same cavity is fully open in the tetragonal structure of $\mathrm{D} 187 \mathrm{~N}_{\mathrm{G} 2}$, where we were able to model only up to residue 255 . The electron density for the calcium site is of poor quality (data not shown), the sidechain of K166 is barely visible and no solvent molecule could be modelled. The orthorhombic and tetragonal structures seem to represent two intermediate states toward the domain's (partial) unfolding.

\subsection{Nb11 binding modulates $C$-terminal disorder allosterically}

Based on our structures, one can hypothesize that Nb11 binding induces $\mathrm{D} 187 \mathrm{~N}_{\mathrm{G} 2}$ in a proteolysis-resistant conformation, but crystallographic analysis alone is not sufficient to assess whether the flexibility of the $\mathrm{D} 187 \mathrm{~N}_{\mathrm{G} 2} \mathrm{C}$-terminal tail and exposure of the calcium cavity lead to its susceptibility to furin proteolysis. To investigate the impact of the mutation on local kinetics or a possible conformational selection effect by Nb11 binding, we analyzed the domain's dynamics via MD simulations. We simulated the $\mathrm{WT}_{\mathrm{G} 2}$ and $\mathrm{D} 187 \mathrm{~N}_{\mathrm{G} 2}$ systems in the presence or absence of bound Nb11 (Table 2), starting from the crystallographic poses reported in PDB: 4S10 (see Materials and methods section).

The most striking result was the fast opening and solvent-exposure of the C-terminus segment, which occurred within the first hundred nanoseconds, in all of the structures of $\mathrm{D} 187 \mathrm{~N}_{\mathrm{G} 2}$ lacking the $\mathrm{Ca}^{2+}$ ion (Table 2). In the crystallographic structures of the $\mathrm{WT}_{\mathrm{G} 2}$ protein, the $\mathrm{C}$ terminal region up until residue 259 lies near the $\beta 1-\beta 2$ hinge loop which hosts the furin cleavage site $\left(\mathrm{R}_{169}-\mathrm{V}-\mathrm{V}-\mathrm{R}_{172}\right)$, indicating a possible steric protection mechanism already suggested by Huff et al. [14]. In consistency with our crystallographic results, MD did not uncover
Table 2

Summary of the molecular dynamics runs. Simulated time and behavior of the C-terminal stretch are reported. "C-terminal disorder onset" indicates the time of onset of C-terminal segment mobility (residue 248 and beyond), defined as R186-T260 distance $>20 \AA$. Afterwards, the C terminal segment ("arm") is solvated and strongly fluctuating.

\begin{tabular}{lcccc}
\hline Sample & Nb11 & $\mathrm{Ca}^{2+}$ & Simulated time (ns) & C-terminal disorder onset \\
\hline $\mathrm{WT}_{\mathrm{G} 2}$ & - & + & 800 & Not observed \\
$\mathrm{WT}_{\mathrm{G} 2}$ & + & + & 750 & Not observed \\
$\mathrm{D} 87 \mathrm{~N}_{\mathrm{G} 2}$ & - & - & 748 & After 83 ns \\
$\mathrm{D} 87 \mathrm{~N}_{\mathrm{G} 2}$ & + & - & 512 & After 40 ns \\
\hline
\end{tabular}

further major "static" structural rearrangements between the $\mathrm{WT}_{\mathrm{G} 2}$, $\mathrm{D} 187 \mathrm{~N}_{\mathrm{G} 2}$ and $\mathrm{D} 187 \mathrm{~N}_{\mathrm{G} 2}: \mathrm{Nb} 11$ in the timescales tested.

Local (residue-wise) fluctuations across the G2 residues (Fig. 4A, red curve) indicate two major areas of destabilization in the $\mathrm{D} 187 \mathrm{~N}_{\mathrm{G} 2}$ with respect to the $\mathrm{WT}_{\mathrm{G} 2}$, namely (a) the region $179-183$ (helix $\alpha 0$ ) is located; and (b) the arm of the domain, i.e. the C-terminal region up to residue 240 including the $\beta 5-\alpha 2$ loop, the $\alpha 2$ helix and the opening Cterminal arm plus its elbow at helix $\alpha 2$. Binding of $\mathrm{Nb} 11$ to the $\mathrm{D} 187 \mathrm{~N}_{\mathrm{G} 2}$ (Fig. 4A, cyan curve) almost entirely abolished the fluctuations in both regions. In other words, Nb11 essentially restores the fluctuation dynamics of the mutant to the low level present in the $\mathrm{WT}_{\mathrm{G} 2}$. The simulation of the $\mathrm{WT}_{\mathrm{G} 2}: \mathrm{Nb} 11$ complex confirmed that the Nb11 does not significantly alter the local stability of the $\mathrm{WT}_{\mathrm{G} 2}$, although it partially stabilizes the $\beta 5-\alpha 2$ region where it binds.

The main molecular events underlying the destabilization induced by the $\mathrm{D} 187 \mathrm{~N}$ mutation are summarized in Fig. 4C. In the absence of $\mathrm{Nb} 11$, the fluctuations in $\mathrm{D} 187 \mathrm{~N}_{\mathrm{G} 2}$ lead to the already described flexibility of the C-terminal tail with the increase of its entropy. Then the transient displacement of the $\alpha 2$ helix occurs, followed by the disruption of the hydrophobic core triad composed by W180, F183 and W200 residues (Supplementary Fig. S2). Noteworthy, the ConSurf algorithm indicates that $\mathrm{F} 183$, belonging to the $\alpha 0$ helix, is strongly conserved in gelsolin-like domains (see Discussion) [46]. Even though binding of $\mathrm{Nb} 11$ has only a minor impact on the resolved pose of the C-terminal 
A

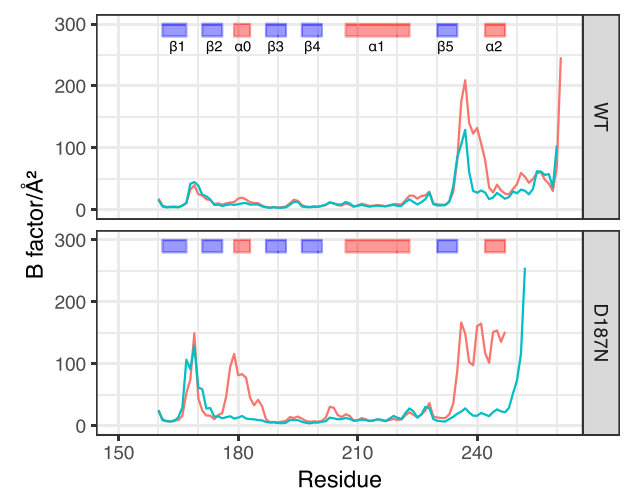

B

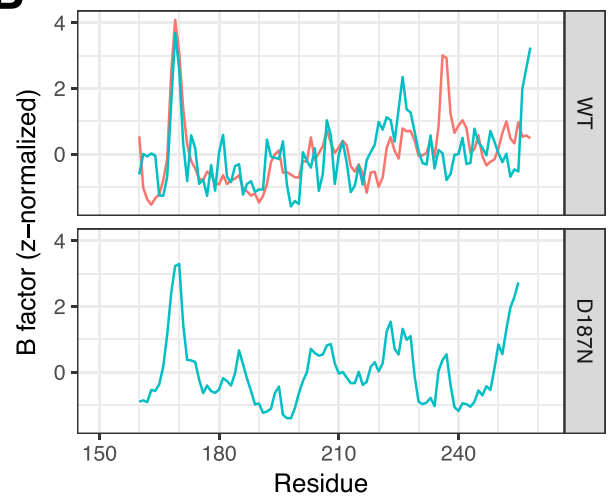

C

$\mathrm{Nb}$

- Nanobody

- +Nanobody

$\mathrm{Nb}$

- Nanobody

- Nanobody
D187N

Reduction of C-terminus entropy

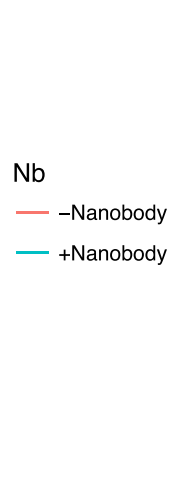

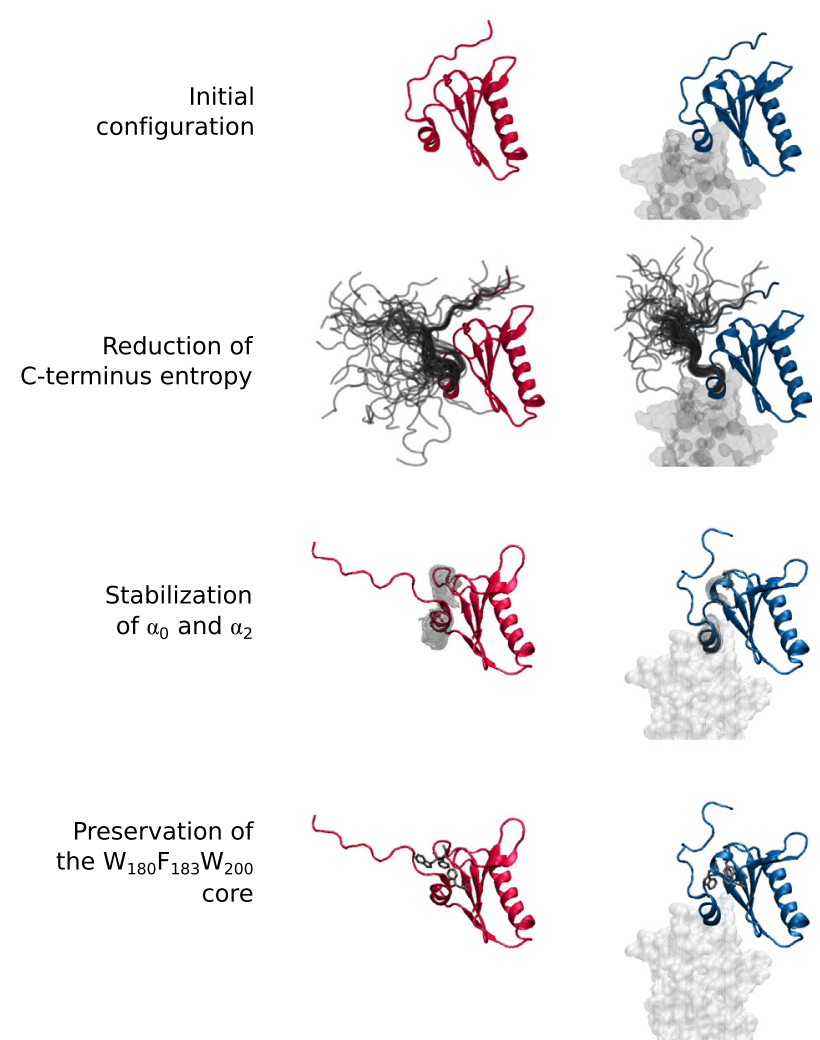

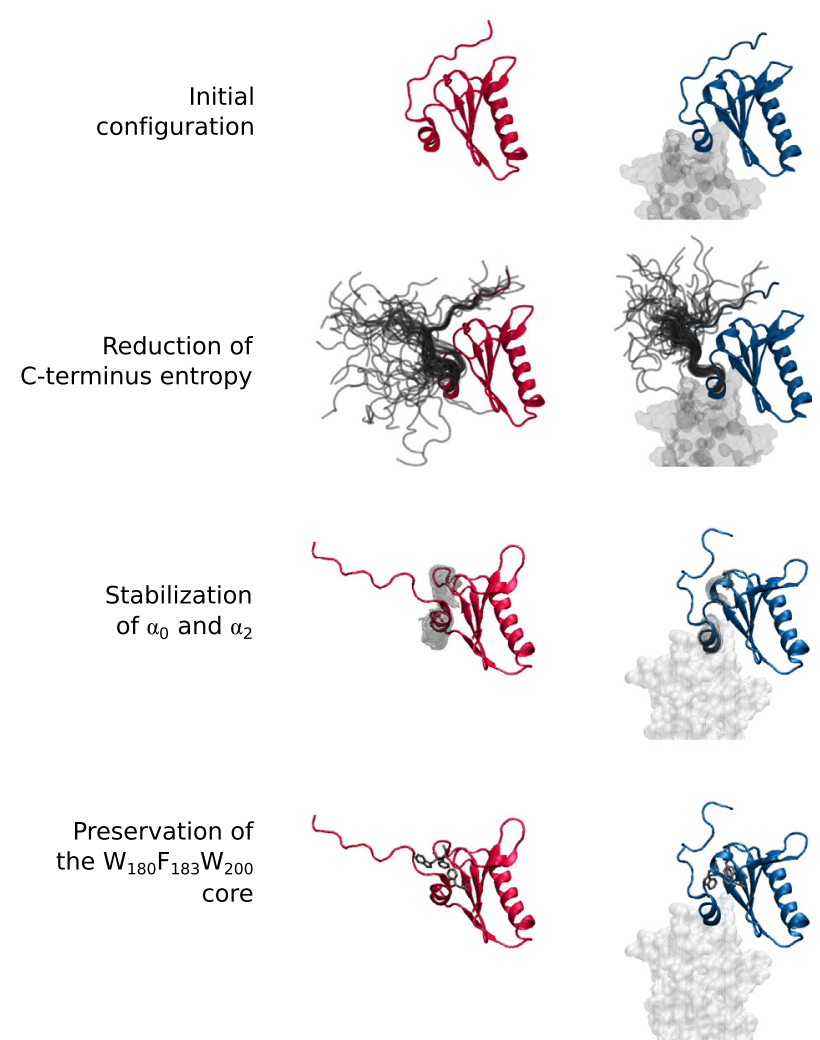

D187N

$+\mathrm{Nb} 11$
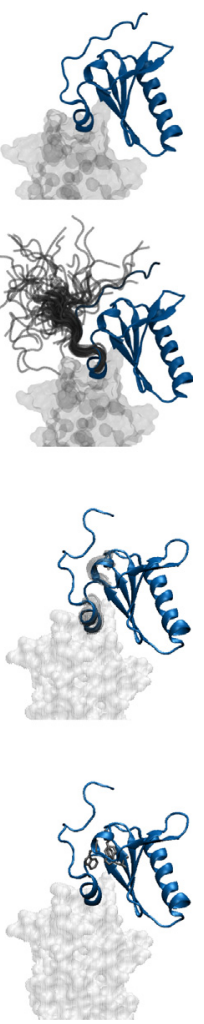

Fig. 4. Dynamics and fluctuations of the $\mathrm{D} 187 \mathrm{~N}_{\mathrm{G} 2}$ variant in the presence or absence of Nb11. A) Plot of the static $B$ factors per residue calculated by the simulation of the $\mathrm{WT}_{\mathrm{G} 2}$ and $\mathrm{D} 187 \mathrm{~N}_{\mathrm{G} 2}$ in the presence (cyan line) or absence (red) of Nb11. Structured regions are indicated in blue ( $\beta$ sheets from $\beta 1$ to $\beta 5$ ) and pink ( $\alpha$ helices $\alpha 0$ to $\alpha 2)$. Furin cleavage site is in the $\beta 1-\beta 2$ loop. B) Normalized $\mathrm{B}$ factors $\left(\mathrm{B}_{\mathrm{z}-\mathrm{score}}\right)$ extracted by the crystallographic structures of $\mathrm{WT}_{\mathrm{G} 2}, \mathrm{WT}_{\mathrm{G} 2}: \mathrm{Nb}_{11}$ and $\mathrm{D} 187 \mathrm{~N}_{\mathrm{G} 2}: \mathrm{Nb} 11$, color-coded as in panel A. C) Overview of the main molecular features and conformational diversity observed during the simulations of D187N $\mathrm{N}_{\mathrm{G} 2}$ in the presence or absence of Nb11 (light grey). Dark grey: snapshots of the disordered C-terminus from the conformational ensemble.

tail, its conformational entropy was reduced compared with $\mathrm{D} 187 \mathrm{~N}_{\mathrm{G} 2}$ alone, thus likely preventing the rearrangement of the $\alpha 2$ helix and the exposure of the core residues.

To validate the computational findings, we further compared the amount of disorder obtained from the simulations with the crystallographic data. Although not ideal to investigate protein dynamics, crystallographic data in the $2 \AA$ resolution range does contain information on the disorder and mobility of the single atoms in the crystal [47]. To this purpose, B factors shown in Fig. 4B were extracted from the structures of $\mathrm{D} 187 \mathrm{~N}_{\mathrm{G} 2}: \mathrm{Nb} 11, \mathrm{WT}_{\mathrm{G} 2}$ (PDB: $1 \mathrm{KCQ}$ ) and $\mathrm{WT}_{\mathrm{G} 2}: \mathrm{Nb} 11$ (PDB: 4S10) (the structure of the $\mathrm{D} 187 \mathrm{~N}_{\mathrm{G} 2}$ variant alone is unavailable). B values were averaged between datasets or symmetric molecules (where available) and normalized to zero mean and unit variance in order to obtain a $\mathrm{B}_{\mathrm{z} \text {-score }}$ comparable between models (Fig. 4B). As expected, we observe a sharp decrease of $\mathrm{WT}_{\mathrm{G} 2}$ and $\mathrm{D} 187 \mathrm{~N}_{\mathrm{G} 2} \mathrm{~B}_{\mathrm{z} \text {-score }}$ at the Nb11 binding interface, indicating that this region becomes less dynamic. Stabilization also propagates through the C-terminus and the $\alpha 2$ helix (that is partly involved in the interaction with $\mathrm{Nb}$ ). The hinge loop formed by amino acid residues 167-170, which hosts the sequence recognized by furin, results very dynamic in both $\mathrm{WT}_{\mathrm{G} 2}$ and $\mathrm{D} 187 \mathrm{~N}_{\mathrm{G} 2}$ structures (with and without Nb11) suggesting that the presence of the mutation does not directly affect the conformation or the stability of this loop.

The MD analysis identified two instability hotspots in the mutated G2 domain: the $\alpha 0$ helix and the stretch comprising $\beta 5-\alpha 2$ loop and $\alpha 2$ helix. In the first region we were not able to detect any significant differences between the structure of the $\mathrm{WT}_{\mathrm{G} 2}$ and that of $\mathrm{D} 187 \mathrm{~N}_{\mathrm{G} 2}$ stabilized by Nb11 (data not shown). As shown in Fig. 3B (left panel), the $\mathrm{WT}_{\mathrm{G} 2} \beta 5-\alpha 2$ loop is connected to the C-terminal tail and the calcium binding site through a solvent-mediated H-bond network. The structure of the mutant reveals a reorganization of the polar contacts mostly due to a drift of the backbone in the 235-239 stretch and the different conformation of side-chains of residues 185 and 236 (Fig. 3B, right panel). Overall, these observations indicate that the $\mathrm{D} 187 \mathrm{~N}$ substitution causes a slight loss in connectivity of the G2 domain essentially due to the loss of the coordinated $\mathrm{Ca}^{2+}$. Major rearrangements observed in the simulations are thus likely prevented by the binding to Nb11, which partly compensates for the loss of the calcium ion and forces the first half of the C terminus of D187N in a WT-like conformation.

\subsection{Nb11 protects all pathogenic GSN variants from aberrant furin proteolysis}

The ability of Nb11 to bind D187N-mutated GSN and to inhibit its proteolysis by furin has been extensively demonstrated in vitro and in vivo [19]. Recently, we have characterized two novel GSN pathogenic variants reported as responsible for a renal localized amyloidosis, G167R and N184K [30,31]. Structural and functional analyses revealed that the $\mathrm{N} 184 \mathrm{~K}$ substitution induces a reorganization of the connection in the core of the G2 domain; contrarily, G167R mutation promotes the dimerization of the protein by a domain swap mechanism. Similarly to D187N, both substitutions impair protein stability and ultimately lead to protein degradation and aggregation. Therefore, we wondered if Nb11 would also be able to bind the variants responsible for the renal disease and protect these proteins against furin proteolysis. The susceptibility to furin proteolysis of full-length WT and the three 


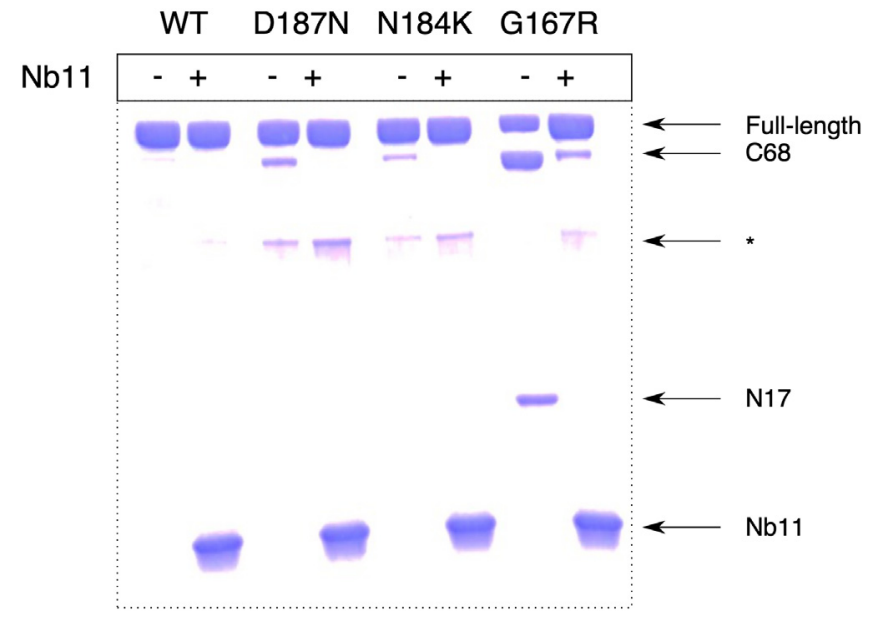

Fig. 5. Effect of Nb11 on the susceptibility of full-length GSN variants to proteolysis. Susceptibility to furin proteolysis of WT, D187N, N184K and G167R variants in their full-length form evaluated in the presence $(+)$ or the absence (-) of Nb11. C68 and N17 are the two fragments produced by furin activity, named after their molecular weight in $\mathrm{kDa}$. *Indicates unspecific proteolysis product due to contaminants.

aforementioned mutants was tested in the presence or the absence of a 6-fold molar excess of Nb11.

Full-length activated (i.e. calcium-bound) GSN is a flexible protein prone to unspecific proteolysis, a phenomenon that is more evident for the mutants (Fig. 5, band marked with *). Its susceptibility to furin cleavage was therefore tested over a short incubation time $(3 \mathrm{~h})$ at $37^{\circ} \mathrm{C}$. Furin activity produces two fragments, the well-known C68 and one here named N17, which is visible only when proteolysis proceed to a larger extent, as is the case for the G167R variant. Nb11 dramatically reduced the susceptibility to furin of all the tested variants, either abolishing any trace of its activity, or significantly slowing down the process.

\subsection{Nb11 stabilizes the mutated G2 fold}

The protection exerted by $\mathrm{Nb} 11$ on the furin proteolysis cannot be simply explained by steric hindrance. Moreover, our structural and computational analyses pointed at a stability modulation effect. To further elucidate the molecular mechanism underlying the action of the nanobody, we assayed Nb11's impact on the thermal stability of the G2 variants. Denaturation of the proteins was induced by a linear temperature gradient (from $20{ }^{\circ} \mathrm{C}$ up to $90^{\circ} \mathrm{C}$ ) and studied by $\mathrm{CD}$ spectroscopy at $218 \mathrm{~nm}$ (sensitive to $\alpha$-helical content) in the presence of saturating calcium concentration. $\mathrm{WT}_{\mathrm{G} 2}$ and all the mutated domains showed a sigmoidal increase in ellipticity upon unfolding (Supplementary Fig. S3). Contrarily, Nb11 signal decreased over time as the immunoglobulin-like domain lacks $\alpha$-helical content. Interpretation of the melting curves of the complexes is therefore hindered by the opposing behavior of the two proteins.

To analyze CD data, we compared the denaturation curve obtained for the G2:Nb11 complex with the arithmetical sum of the experiments performed on the individual subunits of the complex. We hypothesize that, in the case there is no stabilization, the curve of the complex should roughly superimpose to the curve of the sum, because the G2 domain and Nb11 unfold independently. Indeed, this was the behavior observed for the $\mathrm{WT}_{\mathrm{G} 2}$, in which the binding to $\mathrm{Nb11}$ seems not to have any impact on the protein stability (Fig. 6A). In contrast, all the pathological G2 mutants showed significant differences between the denaturation profile of the sum and that of the experimental complex (Fig. 6A).

To quantify the stabilizing effect of Nb11, we performed thermofluor experiments of the G2 domains, whose denaturation is achieved in the presence of a fluorogenic probe (Fig. 6B). As reported in Table 3, the $\mathrm{T}_{\mathrm{m}}$ values for the mutated $\mathrm{G} 2$ domains were lower than that of the $\mathrm{WT}_{\mathrm{G} 2}$ with differences between the $\mathrm{T}_{\mathrm{m}}$ value of $\mathrm{WT}_{\mathrm{G} 2}$ and that of the mutated proteins $\left(\Delta \mathrm{T}_{\mathrm{m}}\right)$ ranging from $12.6{ }^{\circ} \mathrm{C}$ to $17.3^{\circ} \mathrm{C}$. These results are similar to those previously reported, measured by $\mathrm{CD}$ (see Supplementary Table 1) $[10,14,30,31]$. The $\mathrm{WT}_{\mathrm{G} 2}: \mathrm{Nb} 11$ complex unfolds at a lower temperature than the $\mathrm{WT}_{\mathrm{G} 2}$ alone, suggesting the absence of any stabilization induced by Nb11. On the contrary, mutants' thermal stability significantly benefits from Nb11 binding as indicated by the $\Delta \mathrm{T}_{\mathrm{m}}$ values which dropped to $3.1-4.7^{\circ} \mathrm{C}$ (Table 3).

In agreement with the structural observations, these data show that Nb11 protects G2 from aberrant proteolysis reverting the destabilization induced by the mutations. It is noteworthy that both $\mathrm{T}_{\mathrm{m}}$ experimental approaches are insensible to the displacement of the C-terminal tail, because it neither results in a loss of secondary structures nor it leads to the exposure of hydrophobic patches, being the calcium pocket very polar.

\subsection{Nb11 counteracts the proteotoxicity of G2 domains in C. elegans}

It is well known that the administration to nematodes of a toxic compound, such as a misfolded protein, induces a pharyngeal dysfunction $[24,25,28,29]$ that can be evaluated by counting the number of worm's pharyngeal contractions, defined as "pumping rate" [28]. Therefore, we employed $C$. elegans assays to determine whether the structural changes and the stabilizing effects induced by Nb11 on the mutated $\mathrm{G} 2$ variants can also affect their biological properties.

First, we evaluated the ability of $\mathrm{WT}_{\mathrm{G} 2}$ or mutated $\mathrm{G} 2$ to induce a pharyngeal dysfunction in worms. To this end, $250 \mu \mathrm{g} / \mathrm{ml}$ of each protein was administered to worms, and the pharyngeal contraction was determined at different times after the treatment. After $2 \mathrm{~h}$ the pumping rate of $\mathrm{WT}_{\mathrm{G} 2}$-fed worms is significantly reduced compared to those fed vehicle $(228.4 \pm 1.7$ and $217.1 \pm 1.6 \mathrm{pumps} / \mathrm{min}$ for vehicle- and $\mathrm{WT}_{\mathrm{G} 2}$-fed worms, respectively) (Fig. 7A). A greater inhibition was observed in nematodes treated with mutated G2 domains, particularly $\mathrm{N}_{184 \mathrm{~K}_{\mathrm{G} 2}}(177.9 \pm 1.8$ pumps/min $)$ which is significantly more

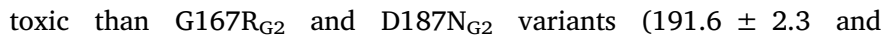
$208.4 \pm 3.0 \mathrm{pumps} / \mathrm{min}$, respectively) (Fig. 7A). These outcomes were comparable to those of worms treated with $10 \mathrm{mM}$ hydrogen peroxide, used as positive stress control $(183.7 \pm 1.6 \mathrm{pumps} / \mathrm{min}, p<0.0001$ $v s$. vehicle, Student's $t$-test), indicating that the reduction of pharyngeal contraction induced by the mutated G2 domains is biologically relevant.

We also observe that the pharyngeal impairment induced by $\mathrm{WT}_{\mathrm{G} 2}$ is transient because the pumping rate scored $24 \mathrm{~h}$ after the administration was similar to that of vehicle-fed nematodes $(233.4 \pm 2.3$ and $225.8 \pm 1.7 \mathrm{pumps} / \mathrm{min}$ for vehicle and $\mathrm{WT}_{\mathrm{G} 2}$, respectively). On the contrary, the mutated G2 domains induced a persistent pharyngeal functional damage, without complete recovery even after $24 \mathrm{~h}$ (Fig. 7B). Whereas the pharyngeal dysfunction induced by $\mathrm{D} 187 \mathrm{~N}_{\mathrm{G} 2}$ did not change over time $(208.4 \pm 3.8$ and $211.3 \pm 3.5$ pumps $/ \mathrm{min}$ at 2 and $24 \mathrm{~h}$, respectively), those caused by $\mathrm{G}_{167 \mathrm{R}_{\mathrm{G} 2}}$ and $\mathrm{N} 184 \mathrm{~K}_{\mathrm{G} 2}$ significantly decreased (Supplementary Fig. 4).

Trying to establish a relationship between protein toxicity and folding, worms were fed with equimolar concentration of either $\mathrm{WT}_{\mathrm{G} 2}$ or $\mathrm{WT}_{\Delta \mathrm{G} 2}$. Lacking the $\beta 1$ strand, $\mathrm{WT}_{\Delta \mathrm{G} 2}$ is unable to properly fold and displays spectroscopy characteristics typical of a natively unfolded protein under physiological conditions [31]. We observed that the unfolded $\mathrm{G} 2$ domain $\left(\mathrm{WT}_{\Delta \mathrm{G} 2}\right)$ was significantly more effective in reducing the pharyngeal pumping than the folded one underlining the relevance of the folding status for the toxicity (Supplementary Fig. 5).

The different toxic potential of the mutated G2 domains is further proven by the experiments evaluating their dose-dependent effects on the pharynx of worms (Fig. 7C-D). IC 50 (half-maximal effect) values calculated $2 \mathrm{~h}$ after the exposure resulted significantly higher for $\mathrm{WT}_{\mathrm{G} 2}$ than for mutated G2 and, among these, the higher toxicity was obtained 
A

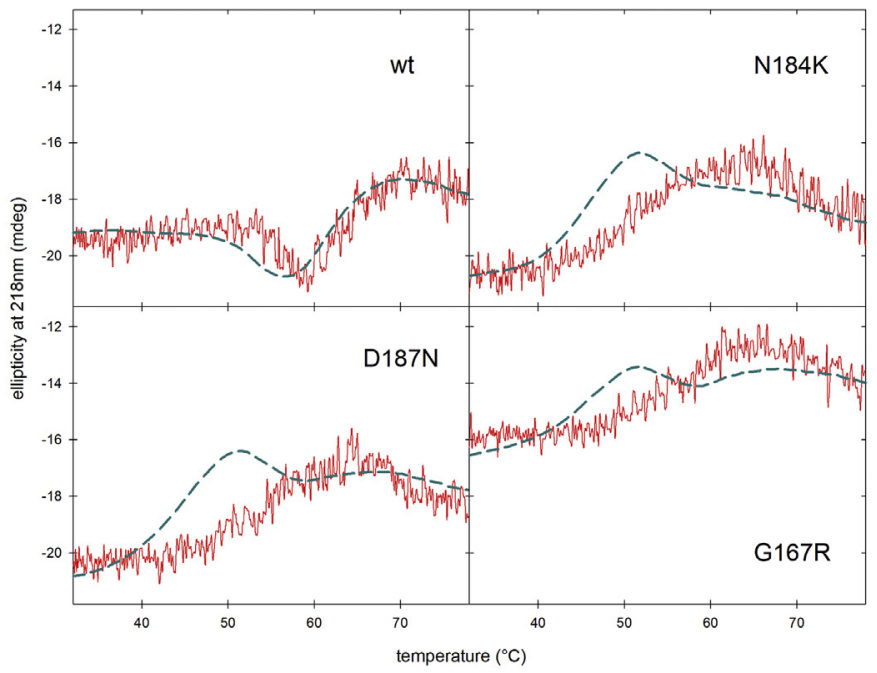

B

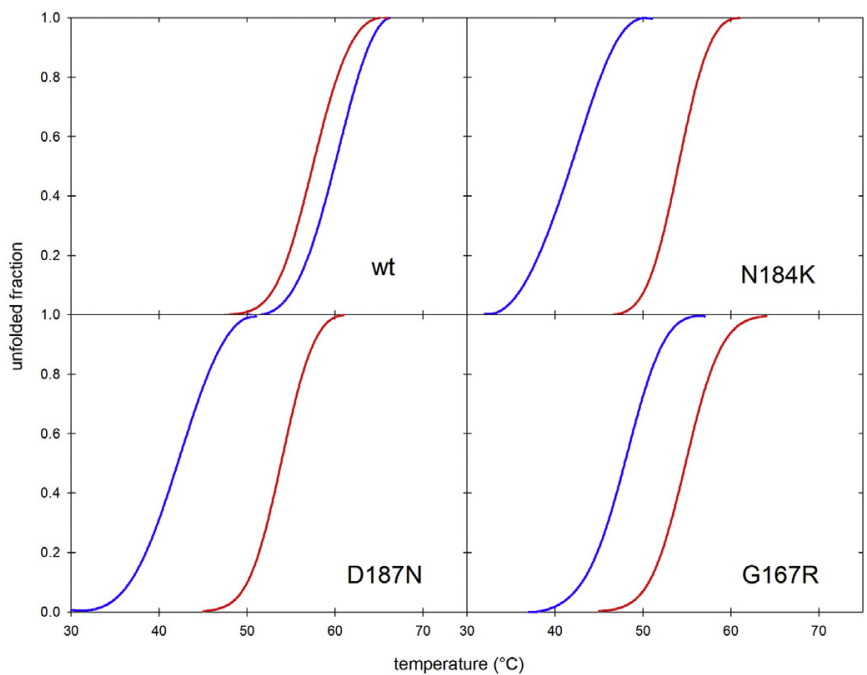

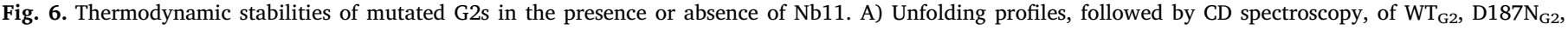

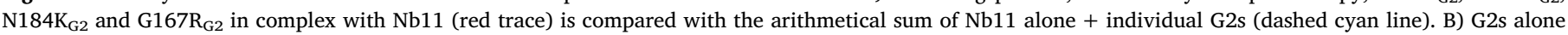

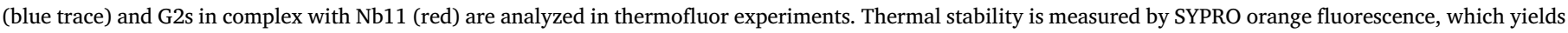
sigmoidal curves typical of a two-state, cooperative denaturation.

Table 3

Quantitative evaluation of the effect of Nb11 on the thermal stability of G2 domains. Apparent $\mathrm{T}_{\mathrm{m}}$ values from thermofluor experiments were calculated as the minimum of the first derivative of the traces in Fig. 6B. Reported values are the average of three independent measurements $\pm \mathrm{SD}$, at most. $\mathrm{T}_{\mathrm{m}}$ for Nb11 alone in the same experimental conditions is $50 \pm 1{ }^{\circ} \mathrm{C}$.

\begin{tabular}{cccccc}
\hline & & $\mathrm{WT}_{\mathrm{G} 2}$ & $\mathrm{G} 167 \mathrm{R}_{\mathrm{G} 2}$ & $\mathrm{~N} 184 \mathrm{~K}_{\mathrm{G} 2}$ & $\mathrm{D} 187 \mathrm{~N}_{\mathrm{G} 2}$ \\
\hline \multirow{2}{*}{$\mathrm{Nb} 11$} & $\mathrm{~T}_{\mathrm{m}}\left({ }^{\circ} \mathrm{C}\right)$ & $60.3 \pm 0.6$ & $47.7 \pm 0.6$ & $43.0 \pm 0.0$ & $44.0 \pm 1.7$ \\
& $\Delta \mathrm{T}_{\mathrm{m}}\left(\mathrm{WT}_{\mathrm{G} 2^{-}}\right.$ & & 12.6 & 17.3 & 16.3 \\
& mutant) & & & & \\
$+\mathrm{Nb} 11$ & $\mathrm{~T}_{\mathrm{m}}\left({ }^{\circ} \mathrm{C}\right)$ & $57.7 \pm 0.6$ & $54.6 \pm 0.6$ & $53.0 \pm 1.0$ & $53.7 \pm 0.6$ \\
& $\Delta \mathrm{T}_{\mathrm{m}}\left(\mathrm{W} \mathrm{T}_{\mathrm{G} 2^{-}}\right.$ & & 3.1 & 4.7 & 4.0 \\
& mutant) & & & & \\
\hline
\end{tabular}

for $\mathrm{N}_{184 \mathrm{~K}_{\mathrm{G} 2}}$ (Table 4). Similar $\mathrm{IC}_{50}$ values are calculated after $24 \mathrm{~h}$ for $\mathrm{G}_{167 \mathrm{R}_{\mathrm{G} 2}}$ and $\mathrm{D} 187 \mathrm{~N}_{\mathrm{G} 2}$ whereas a 4-fold increase is observed for N184K $\mathrm{G}_{2}$ (Table 4).

These findings indicate that $C$. elegans can efficiently recognize the proteotoxic potential of $\mathrm{G} 2$ domains, pointing to its use as a rapid and valuable tool to investigate the mechanisms underlying AGel. Also, the different proteotoxic abilities exerted by the various mutated G2 domains suggests that each mutation may drive a specific damage.

The effect of Nb11 on the pharyngeal toxicity induced by the G2 domains was then investigated. For these experiments, worms were fed $250 \mu \mathrm{g} / \mathrm{ml}$ of $\mathrm{WT}_{\mathrm{G} 2}$ or $\mathrm{D} 187 \mathrm{~N}_{\mathrm{G} 2}$ (corresponding to $19 \mu \mathrm{M}$ ), $100 \mu \mathrm{g} / \mathrm{ml}$ of

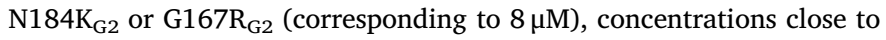
the $\mathrm{IC}_{50}$ value calculated for the $2 \mathrm{~h}$ of exposure (Table 3). G2s were administered alone or as complexes with an equimolar concentration of $\mathrm{Nb11}$. Although Nb11 alone caused a significant reduction of the pharyngeal function, both its toxicity as well as those of G2 domains scored $2 \mathrm{~h}$ after administration were neutralized when co-administered (Fig. 7E). Noteworthy, the effect of $\mathrm{Nb} 11$ on the toxicity induced by the mutated G2 domains were still present $24 \mathrm{~h}$ after the treatment (Supplementary Fig. 6) as an indication of sustained protective action.

These data indicate that the structural and molecular effects induced by $\mathrm{Nb} 11$ on the G2 variants can translate into a biologically relevant effect in vivo. $\mathrm{Nb} 11$ can bind and chaperone the $\mathrm{D} 187 \mathrm{~N}_{\mathrm{G} 2}$ as well as the $\mathrm{G} 2$ domains of the renal variants counteracting their proteotoxic potential.

\section{Discussion}

The current model of the pathological mechanism underlying AGel amyloidosis is mostly based on studies performed on the D187N-mutated protein and experiments conducted in vitro and in vivo on transgenic animals expressing this variant $[15,16,48]$. Results obtained with D187N likely also apply to the later discovered Danish variant (D187Y), although some differences were reported [49]. On the contrary, the mechanism underlying the recently discovered renal disease associated with the N184K and G167R mutations have not been fully elucidated. Interestingly, while the crystallographic structures of isolated G2 domains carrying the N184K or G167R mutation are already available $[30,31]$, until now the D187N/Y structural characterization had not been elucidated.

We here demonstrated that crystallization of the D187N G2 domain was possible only in complex with a previously developed nanobody, called Nb11 [19]. Nb11 tightly binds to gelsolin and protects the D187N variant from aberrant furin proteolysis. In the analysis of the crystal structure, we must consider that the binding of Nb11 somehow biases our model. Indeed, we are observing a proteolysis-resistant species that lost, to some extent, the structural determinants of its proteotoxicity.

To elucidate the mechanism of protection exerted by $\mathrm{Nb} 11$ it is necessary to understand the pathological mechanism of D187N mutation (and vice versa). Clearly, Nb11 acts as a protective chaperone; however, the molecular mechanism behind such function was as yet unclear, mainly because Nb11 binds G2 in a position distant from the furin cleavage site (Fig. 2). Regarding the D187N mutation, a large body of literature is already available, and these studies converged to a general agreement, i.e. that the $\mathrm{D} 187 \mathrm{~N}$ substitution disrupts calcium binding in G2 and the thermodynamic stability of the mutant is decreased to levels similar to those of the WT protein deprived of calcium $[10-12,49]$. Ultimately the mutation leads to the exposure of an otherwise buried sequence, which is aberrantly cleaved by furin. However, the correlation between calcium binding impairment and susceptibility to proteolysis has been the object of discussion. One hypothesis is that the mutation somehow induces a conformational change of the native state that leads to the exposure of the furin site. Another possibility is that the loss of coordinated calcium increases the population of (partially) unfolded protein, which is generally prone to 

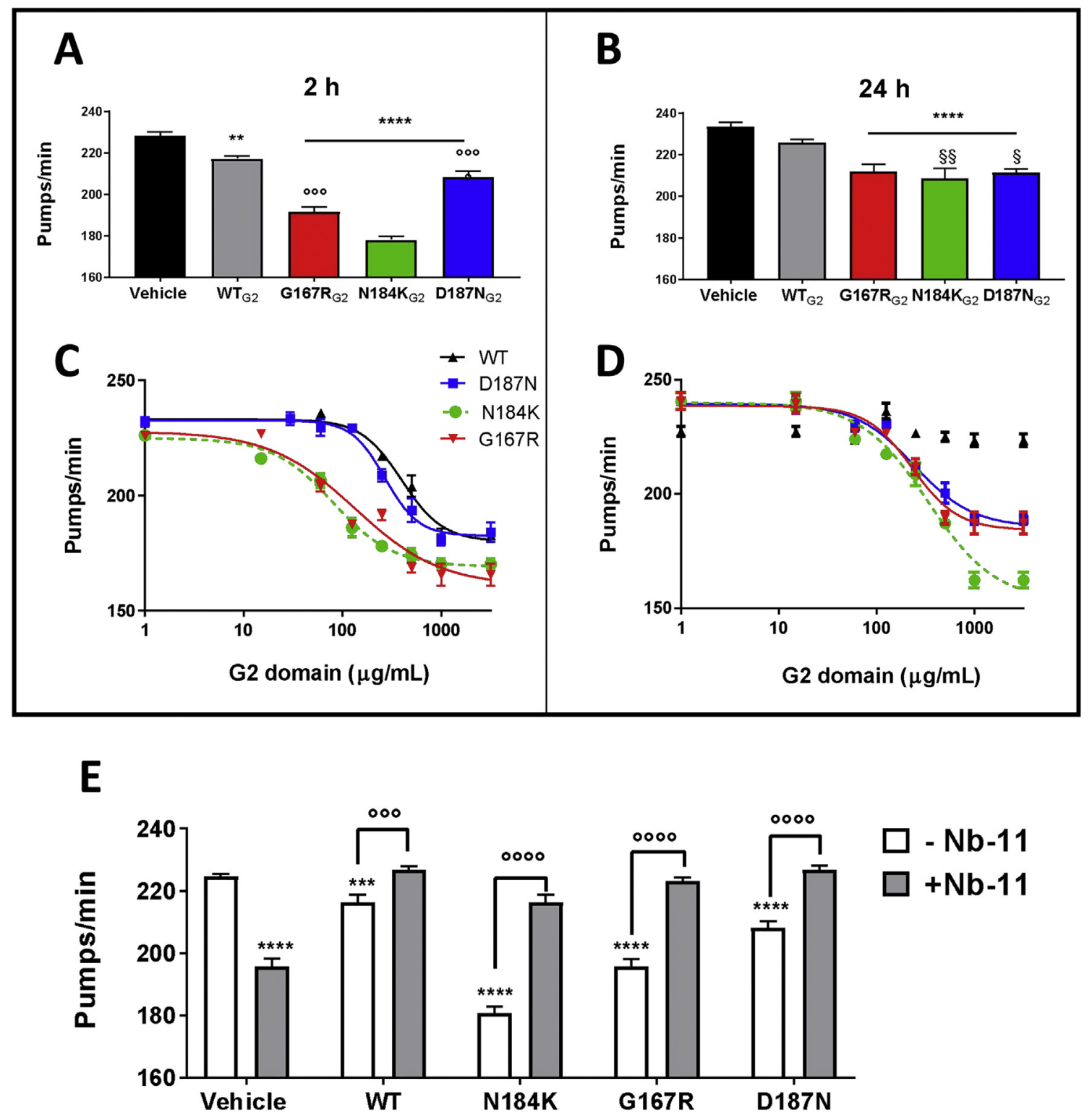

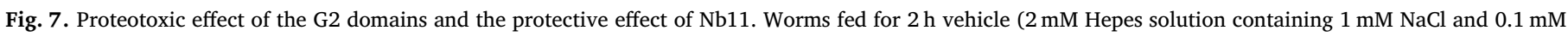

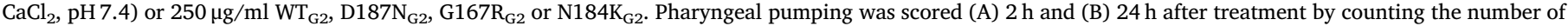

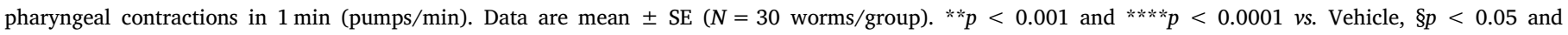

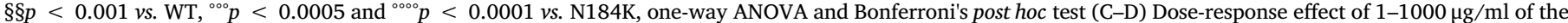

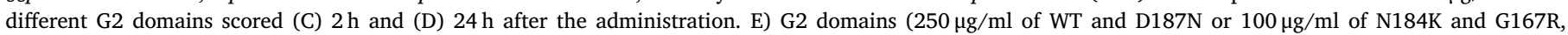

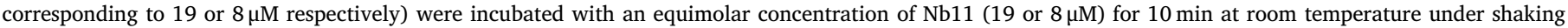

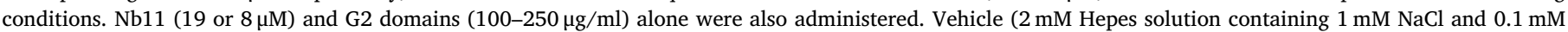

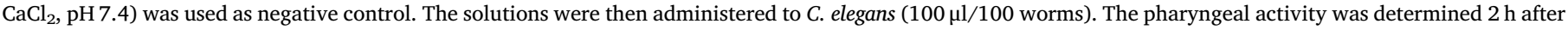

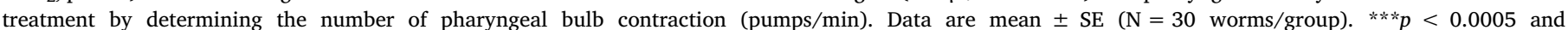

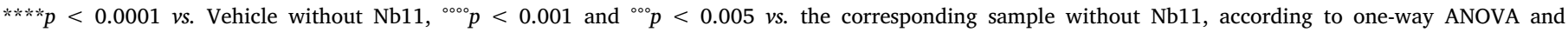

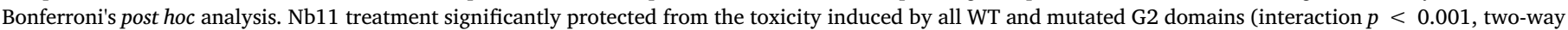
ANOVA and Bonferroni's post hoc analysis).

proteolysis [10-12,49]. The partial disorder hypothesis is consistent with the crystallographic structures, the thermodynamic data as well as with the MD results, which in the absence of the coordinated cation show a fast (on a timescale of tens of ns) opening of the C-terminal stretch. Calcium-mediated disorder-to-order induction has been shown, e.g. in sortase [50,51], adenylate cyclase toxin [52], and possibly several others [53,54].

Interestingly, Kazmirsky and coworkers came to a similar conclusion through a detailed NMR analysis of the D187N variant [12]. In the study, they suggested that the C-terminal tail of the pathogenic variant might be less structured compared to the WT. It might be tempting to explain the increased susceptibility to proteolysis solely based on the flexibility of the C-terminus, which indeed interacts with the hinge loop and exerts some steric protection. However, even the crystallographic structures of the $\mathrm{D} 187 \mathrm{~N}_{\mathrm{G} 2}: \mathrm{Nb} 11$ complex reveal a destabilized tail, and the simulations show a similar dynamic behavior of the stretch irrespective of Nb11 binding. Destabilization of the C-terminus might likely be a necessary condition, but it seems not to be sufficient for the efficient proteolytic cleavage.

In conclusion, we believe that the destabilization of the C-terminal tail is the direct consequence of the loss of the $\mathrm{Ca}^{2+}$ ion induced by D187N mutation. Such increased flexibility is the first event that 
Table 4

Pumping rates and $\mathrm{IC}_{50}$ values of WT and mutated $\mathrm{G} 2$ domains. $\mathrm{IC}_{50}$ values were calculated from the dose-response curves (Fig. 7C/D).

\begin{tabular}{lcc}
\hline Treatment & $\mathrm{IC}_{50}(\mu \mathrm{g} / \mathrm{ml}) \pm \mathrm{SE}$ \\
\cline { 2 - 3 } & $2 \mathrm{~h}$ & $24 \mathrm{~h}$ \\
\hline $\mathrm{WT}_{\mathrm{G} 2}$ & $398.5 \pm 1.12$ & Not interpolated \\
$\mathrm{D} 187 \mathrm{~N}_{\mathrm{G} 2}$ & $273.0 \pm 1.09^{*}$ & $241.8 \pm 1.24$ \\
$\mathrm{~N} 184 \mathrm{~K}_{\mathrm{G} 2}$ & $79.7 \pm 1.12^{* * * * *}$ & $334.5 \pm 1.19^{\circ}$ \\
$\mathrm{G}^{167 \mathrm{R}_{\mathrm{G} 2}}$ & $133.9 \pm 1.20^{* * *}$ & $170.2 \pm 1.21$ \\
\hline
\end{tabular}

$$
\begin{aligned}
& { }^{*} p<0.05 \\
& { }^{* * *} p<0.0005 \\
& { }^{* * * * *} p<0.0001 \text { vs. WT, } \\
& { }^{*} p<0.05 \text { vs. G167R, one-way ANOVA and Bonferroni post hoc test. }
\end{aligned}
$$

triggers the sequential opening of the gelsolin fold, which results in the exposure of residues of the hydrophobic core. The process is likely reversible and this partially unfolded state of the protein is susceptible to furin proteolysis. In the complex with $\mathrm{Nb} 11$, the binding interface, including $\alpha 0$ and $\alpha 2$-loop- $\beta 5$, becomes more rigidly anchored to the proper WT conformation. The latter Nb11-stabilized region lies at the base of the disorder-prone $\mathrm{C}$ terminus, forming an elbow of sorts. We speculate that Nb11 stabilization reverses, at least in part, the entropy gain due to the abolished coordination of $\mathrm{Ca}^{2+}$.

Even though Nb11 was raised against WT gelsolin, it was shown to bind the D187N variant as well, with a slightly lower affinity [19]. Crystallographic structures of N184K and G167R variants, as isolated G2 as well, are also available [30,31]. N184K neither impairs calcium binding nor it significantly destabilizes the C-terminal tail. Loss of conformational stability of N184K-mutated G2 comes from the rearrangement of the polar contacts, which the mutated residue is part of, in the core of the domain. As for the D187N/Y case, N184K mutation eventually leads to furin proteolysis. Contrarily, the pathological mechanism underlying the G167R-dependent disease is still to be fully elucidated. An alternative amyloidogenic pathway has in fact been proposed based on the observation that this variant dimerizes via a domain-swap mechanism [31]. At the same time, even the G167R mutant is prone to aberrant proteolysis and shows impaired thermal stability.

The $\mathrm{WT}_{\mathrm{G} 2}$ and $\mathrm{D} 187 \mathrm{~N}$ - and $\mathrm{N} 184 \mathrm{~K}$-mutated variants share a high structural conservation. The Nb11 binding interface of the $\mathrm{G}_{167 \mathrm{R}_{\mathrm{G} 2}}$ variant is not affected by its dimerization. As a consequence, it comes as no surprise that $\mathrm{Nb11}$ binds the renal variants with similar efficiency. On the contrary, the protection from proteolysis of the N184K and G167R mutants would have been difficult to predict because the impact of these substitutions on the G2 dynamics as well as the mechanism of destabilization is significantly different.

We tested Nb11 protection of the renal variants in standard furin assays and observed indirect inhibition of the protease activity comparable to that of the D187N variant. To further investigate this aspect, we aimed at testing Nb11's activity on mutated G2 in a more biological context. As neither an animal nor a cell model of renal AGel amyloidosis is currently available, we employed a nematode-based assay already developed and validated by our group and already successfully used to determine the toxicity of different amyloidogenic proteins and investigate the mechanisms underlying their proteotoxic effect [24-27,29]. This is based on the knowledge that the rhythmic contraction and relaxation of the $C$. elegans pharynx, the organ fundamental for the worm's feeding and survival, is sensitive to molecules that can act as "chemical stressors" such as some proteins induced in stress conditions. We here showed for the first time that all isolated G2, at concentrations similar to those observed as circulating in humans [55] can cause a biologically relevant toxic effect recognized by $C$. elegans. Whereas $\mathrm{WT}_{\mathrm{G} 2}$ only induced a transient reduction of the pharyngeal pumping, all the pathological mutants caused an impairment which persisted still after $24 \mathrm{~h}$, suggesting that these proteins caused a permanent tissue damage.

Interestingly, $\mathrm{Nb} 11$, which was able to bind and chaperone all the disease-causing mutant forms of GSN and prevent their aberrant proteolysis, completely abolished the proteotoxic effects induced by G2 domains in worms. Although the mechanisms underlying the ability of C. elegans to recognize G2 domain as toxic remains to be elucidated, these findings are consistent with the hypothesis that the toxicity can be ascribed to the partially unfolded status of the proteins and that Nb11 hides the structural determinant of toxicity. The involvement of the folding status in G2 toxicity was further assessed by using a protein totally unfolded due to the truncation of residues 151-167. The toxic effect caused by $\mathrm{WT}_{\Delta \mathrm{G} 2}$ protein on the pharynx of worms was greater and more persistent than that observed with the folded $\mathrm{WT}_{\mathrm{G} 2}$. Additional studies are required to fully elucidate the mechanisms underlying the toxicity of G2 domains on the C. elegans pharynx.

The knowledge of high-resolution determinants of D187N toxicity and the therapeutic action of Nb11 may contribute to the ongoing efforts in the expansion of the currently limited landscape of therapeutic interventions against FAF and other amyloidosis-related diseases. The use of the C. elegans-based assay for the evaluation of the proteotoxic potential of the G2 domains offers unprecedented opportunities to investigate the molecular mechanisms underlying the AGel forms caused by different GSN variants. This model can also be employed for rapidly screen the protective effect of novel or repurposed drugs thus accelerating the identification of an effective therapy against AGel amyloidosis.

\section{Conclusions}

Nb11 works as a pharmacological chaperone (sometimes referred to as pharmacoperone), a concept originally formulated in the context of small chemicals, rather than macromolecules. Such chaperones restore mutated proteins' function or prevent misfolding, either stabilizing the native fold, or assisting the folding process. Although the pharmacoperone concept has been around for a while, only a limited number of successful examples can be found in literature [56-58], and very few drugs belonging to this family are available on the market. Nb11 is, in our knowledge, the first case of a pharmacoperone-like nanobody whose efficacy has been proven in vivo. Contrary to other previously developed pharmacological chaperones, which are mutation-specific, $\mathrm{Nb} 11$ protects all gelsolin pathological variants identified so far, irrespective of the different pathways or mechanisms leading to their degradation and/or aggregation. Furthermore, disease-causing mutations yield proteins which are at times difficult to express and purify, due to their solubility, instability or toxicity. Our data show that pharmacological chaperones can be developed using the WT protein as a target, aiming at the stabilization of the native-like conformation, thus increasing the number of diseases that can be potentially tackled with an analogous strategy. Wide-spectrum applicability is of pivotal importance in view of the potential application of Nbs in therapy.

\section{Transparency document}

The Transparency document associated with this article can be found, in online version.

\section{Acknowledgements}

This research was supported by the Amyloidosis Foundation (Michigan, United States) thanks to a Research Grant to MdR. C. elegans and OP50 E. coli were provided by the Caenorhabditis Genetics Center (CGC) which is funded by NIH Office Research Infrastructure Programs (P40 OD010440). TG acknowledges funding from Acellera Ltd. and Università degli Studi dell'Insubria, Italy, and CINECA awards under the ISCRA initiative for the availability of high performance computing 
resources and support (projects MiXT and Insk2). This work was partially supported by Fondazione Sacchetti, Italy (LD, Grant 2017-2018). The diffraction experiments were performed on beamline ID23-1 at the European Synchrotron Radiation Facility (ESRF), Grenoble, France. We are grateful to local contact at the ESRF for providing assistance in using their beamline.

\section{Financial \& competing interests' disclosure}

Prof. Dr. Jan Gettemans has a financial and/or business interests in Gulliver Biomed BVBA, a company that may be affected by the research reported in the enclosed paper.

\section{Author contribution statement}

TG, JG, LD and MdR: conceptualization, methodology, supervision. TG, AB, MM, EM, AV, JG, LD and MdR: formal analysis, writing original draft. TG, DM, AH, MM, AB, MMB and MdR: investigation. All authors: writing - review and editing.

\section{Appendix A. Supplementary data}

Supplementary data to this article can be found online at https:// doi.org/10.1016/j.bbadis.2019.01.010.

\section{References}

[1] J. Meretoja, Familial systemic paramyloidosis with lattice dystrophy of the cornea, progressive cranial neuropathy, skin changes and various internal symptoms. A previously unrecognized heritable syndrome, Ann. Clin. Res. 1 (1969) 314-324 https://www.ncbi.nlm.nih.gov/pubmed/4313418.

[2] A. de la Chapelle, R. Tolvanen, G. Boysen, J. Santavy, L. Bleeker-Wagemakers, C.P. Maury, J. Kere, Gelsolin-derived familial amyloidosis caused by asparagine or tyrosine substitution for aspartic acid at residue 187, Nat. Genet. 2 (1992) 157-160, https://doi.org/10.1038/ng1092-157.

[3] C.P. Maury, J. Kere, R. Tolvanen, A. de la Chapelle, Finnish hereditary amyloidosis is caused by a single nucleotide substitution in the gelsolin gene, FEBS Lett. 276 (1990) 75-77 https://www ncbi.nlm.nih gov/pubmed/2176164.

[4] J.D. Sipe, M.D. Benson, J.N. Buxbaum, S.-I. Ikeda, G. Merlini, M.J.M. Saraiva, P. Westermark, Amyloid fibril proteins and amyloidosis: chemical identification and clinical classification International Society of Amyloidosis 2016 Nomenclature Guidelines, Amyloid 23 (2016) 209-213, https://doi.org/10.1080/13506129.2016. 1257986.

[5] S. Sethi, S. Dasari, M.S. Amin, J.A. Vrana, J.D. Theis, M.P. Alexander, P.J. Kurtin, Clinical, biopsy, and mass spectrometry findings of renal gelsolin amyloidosis, Kidney Int. 91 (2017) 964-971, https://doi.org/10.1016/j.kint.2016.11.017.

[6] S. Sethi, J.D. Theis, P. Quint, W. Maierhofer, P.J. Kurtin, A. Dogan, E.W. Highsmith Jr., Renal amyloidosis associated with a novel sequence variant of gelsolin, Am. J. Kidney Dis. 61 (2013) 161-166, https://doi.org/10.1053/j.ajkd.2012.07.016.

[7] Y.A. Efebera, A. Sturm, E.C. Baack, C.C. Hofmeister, A. Satoskar, T. Nadasdy, G. Nadasdy, D.M. Benson, J.D. Gillmore, P.N. Hawkins, D. Rowczenio, Novel gelsolin variant as the cause of nephrotic syndrome and renal amyloidosis in a large kindred, Amyloid 21 (2014) 110-112, https://doi.org/10.3109/13506129.2014. 891502.

[8] C.M. Ida, X. Yan, M.E. Jentoft, N.S. Kip, B.W. Scheithauer, J.M. Morris, A. Dogan, J.E. Parisi, K. Kovacs, Pituicytoma with gelsolin amyloid deposition, Endocr. Pathol. 24 (2013) 149-155, https://doi.org/10.1007/s12022-013-9254-y.

[9] A. Srivastava, J. Singh, S.P. Singh Yadav, P. Arya, F. Kalim, P. Rose, Ashish, B. Kundu, The gelsolin pathogenic D187N mutant exhibits altered conformational stability and forms amyloidogenic oligomers, Biochemistry 57 (2018) 2359-2372, https://doi.org/10.1021/acs.biochem.8b00039.

[10] S.L. Kazmirski, R.L. Isaacson, C. An, A. Buckle, C.M. Johnson, V. Daggett, A.R. Fersht, Loss of a metal-binding site in gelsolin leads to familial amyloidosisFinnish type, Nat. Struct. Biol. 9 (2002) 112-116, https://doi.org/10.1038/nsb745.

[11] R.L. Isaacson, A.G. Weeds, A.R. Fersht, Equilibria and kinetics of folding of gelsolin domain 2 and mutants involved in familial amyloidosis-Finnish type, Proc. Natl. Acad. Sci. U. S. A. 96 (1999) 11247-11252 https://www.ncbi.nlm.nih.gov/ pubmed/10500162.

[12] S.L. Kazmirski, M.J. Howard, R.L. Isaacson, A.R. Fersht, Elucidating the mechanism of familial amyloidosis- Finnish type: NMR studies of human gelsolin domain 2, Proc. Natl. Acad. Sci. U. S. A. 97 (2000) 10706-10711, https://doi.org/10.1073/ pnas.180310097.

[13] S. Nag, Q. Ma, H. Wang, S. Chumnarnsilpa, W.L. Lee, M. Larsson, B. Kannan, M. Hernandez-Valladares, L.D. Burtnick, R.C. Robinson, $\mathrm{Ca}^{2+}$ binding by domain 2 plays a critical role in the activation and stabilization of gelsolin, Proc. Natl. Acad. Sci. U. S. A. 106 (2009) 13713-13718, https://doi.org/10.1073/pnas.0812374106.

[14] M.E. Huff, L.J. Page, W.E. Balch, J.W. Kelly, Gelsolin domain $2 \mathrm{Ca}^{2+}$ affinity determines susceptibility to furin proteolysis and familial amyloidosis of Finnish type, J. Mol. Biol. 334 (2003) 119-127 https://www.ncbi.nlm.nih.gov/pubmed/ 14596804.

[15] C.D. Chen, M.E. Huff, J. Matteson, L. Page, R. Phillips, J.W. Kelly, W.E. Balch, Furin initiates gelsolin familial amyloidosis in the Golgi through a defect in $\mathrm{Ca}(2+)$ stabilization, EMBO J. 20 (2001) 6277-6287, https://doi.org/10.1093/emboj/20. 22.6277 .

[16] L.J. Page, J.Y. Suk, M.E. Huff, H.-J. Lim, J. Venable, J. Yates, J.W. Kelly, W.E. Balch, Metalloendoprotease cleavage triggers gelsolin amyloidogenesis, EMBO J. 24 (2005) 4124-4132, https://doi.org/10.1038/sj.emboj.7600872.

[17] J.P. Solomon, I.T. Yonemoto, A.N. Murray, J.L. Price, E.T. Powers, W.E. Balch, J.W. Kelly, The 8 and $5 \mathrm{kDa}$ fragments of plasma gelsolin form amyloid fibrils by a nucleated polymerization mechanism, while the $68 \mathrm{kDa}$ fragment is not amyloidogenic, Biochemistry 48 (2009) 11370-11380, https://doi.org/10.1021/ bi901368e.

[18] C.P. Maury, E.L. Nurmiaho-Lassila, H. Rossi, Amyloid fibril formation in gelsolinderived amyloidosis. Definition of the amyloidogenic region and evidence of accelerated amyloid formation of mutant Asn-187 and Tyr-187 gelsolin peptides, Lab. Investig. 70 (1994) 558-564 https://www.ncbi.nlm.nih.gov/pubmed/8176895.

[19] W. Van Overbeke, J. Wongsantichon, I. Everaert, A. Verhelle, O. Zwaenepoel, A. Loonchanta, L.D. Burtnick, A. De Ganck, T. Hochepied, J. Haigh, C. Cuvelier, W. Derave, R.C. Robinson, J. Gettemans, An ER-directed gelsolin nanobody targets the first step in amyloid formation in a gelsolin amyloidosis mouse model, Hum Mol. Genet. 24 (2015) 2492-2507, https://doi.org/10.1093/hmg/ddv010.

[20] A. Verhelle, N. Nair, I. Everaert, W. Van Overbeke, L. Supply, O. Zwaenepoel, C. Peleman, J. Van Dorpe, T. Lahoutte, N. Devoogdt, W. Derave, M.K. Chuah, T. VandenDriessche, J. Gettemans, AAV9 delivered bispecific nanobody attenuates amyloid burden in the gelsolin amyloidosis mouse model, Hum. Mol. Genet. 26 (2017) 3030, https://doi.org/10.1093/hmg/ddx207.

[21] W. Van Overbeke, A. Verhelle, I. Everaert, O. Zwaenepoel, J. Vandekerckhove, C. Cuvelier, W. Derave, J. Gettemans, Chaperone nanobodies protect gelsolin against MT1-MMP degradation and alleviate amyloid burden in the gelsolin amyloidosis mouse model, Mol. Ther. 22 (2014) 1768-1778, https://doi.org/10.1038/ mt.2014.132.

[22] A. Verhelle, W. Van Overbeke, C. Peleman, R. De Smet, O. Zwaenepoel, T. Lahoutte, J. Van Dorpe, N. Devoogdt, J. Gettemans, Non-invasive imaging of amyloid deposits in a mouse model of AGel using Tc-modified nanobodies and SPECT/CT, Mol. Imaging Biol. 18 (2016) 887-897, https://doi.org/10.1007/s11307-016-0960-y.

[23] E. Pardon, T. Laeremans, S. Triest, S.G.F. Rasmussen, A. Wohlkönig, A. Ruf, S. Muyldermans, W.G.J. Hol, B.K. Kobilka, J. Steyaert, A general protocol for the generation of nanobodies for structural biology, Nat. Protoc. 9 (2014) 674-693, https://doi.org/10.1038/nprot.2014.039.

[24] L. Diomede, P. Rognoni, F. Lavatelli, M. Romeo, E. del Favero, L. Cantù, E. Ghibaudi, A. di Fonzo, A. Corbelli, F. Fiordaliso, G. Palladini, V. Valentini, V. Perfetti, M. Salmona, G. Merlini, A Caenorhabditis elegans-based assay recognizes immunoglobulin light chains causing heart amyloidosis, Blood 123 (2014) 3543-3552, https://doi.org/10.1182/blood-2013-10-525634.

[25] Y. Zeinolabediny, F. Caccuri, L. Colombo, F. Morelli, M. Romeo, A. Rossi, S. Schiarea, C. Ciaramelli, C. Airoldi, R. Weston, L. Donghui, J. Krupinski, R. Corpas, E. García-Lara, S. Sarroca, C. Sanfeliu, M. Slevin, A. Caruso, M. Salmona, L. Diomede, HIV-1 matrix protein p17 misfolding forms toxic amyloidogenic assemblies that induce neurocognitive disorders, Sci. Rep. 7 (2017) 10313, , https:// doi.org/10.1038/s41598-017-10875-0.

[26] L. Diomede, M. Romeo, P. Rognoni, M. Beeg, C. Foray, E. Ghibaudi, G. Palladini, R.A. Cherny, L. Verga, G.L. Capello, V. Perfetti, F. Fiordaliso, G. Merlini, M. Salmona, Cardiac light chain amyloidosis: the role of metal ions in oxidative stress and mitochondrial damage, Antioxid. Redox Signal. 27 (2017) 567-582, https://doi.org/10.1089/ars.2016.6848.

[27] M. Stravalaci, A. Bastone, M. Beeg, A. Cagnotto, L. Colombo, G. Di Fede, F. Tagliavini, L. Cantù, E. Del Favero, M. Mazzanti, R. Chiesa, M. Salmona, L. Diomede, M. Gobbi, Specific recognition of biologically active amyloid- $\beta$ oligomers by a new surface plasmon resonance-based immunoassay and an in vivo assay in Caenorhabditis elegans, J. Biol. Chem. 287 (2012) 27796-27805, https://doi.org/ 10.1074/jbc.M111.334979.

[28] D. Jones, E.P. Candido, Feeding is inhibited by sublethal concentrations of toxicants and by heat stress in the nematode Caenorhabditis elegans: relationship to the cellular stress response, J. Exp. Zool. 284 (1999) 147-157 https://www.ncbi.nlm.nih. gov/pubmed/10404644.

[29] M. Romeo, M. Stravalaci, M. Beeg, A. Rossi, F. Fiordaliso, A. Corbelli, M. Salmona, M. Gobbi, A. Cagnotto, L. Diomede, Humanin specifically interacts with amyloid- $\beta$ oligomers and counteracts their in vivo toxicity, J. Alzheimers Dis. 57 (2017) 857-871, https://doi.org/10.3233/JAD-160951.

[30] F. Bonì, M. Milani, R. Porcari, A. Barbiroli, S. Ricagno, M. de Rosa, Molecular basis of a novel renal amyloidosis due to N184K gelsolin variant, Sci. Rep. 6 (2016) 33463, , https://doi.org/10.1038/srep33463.

[31] F. Bonì, M. Milani, A. Barbiroli, L. Diomede, E. Mastrangelo, M. de Rosa, Gelsolin pathogenic Gly167Arg mutation promotes domain-swap dimerization of the protein, Hum. Mol. Genet. 27 (2018) 53-65, https://doi.org/10.1093/hmg/ddx383.

[32] W. Kabsch, XDS, Acta Crystallogr. D Biol. Crystallogr. 66 (2010) 125-132, https:// doi.org/10.1107/S0907444909047337.

[33] P.R. Evans, G.N. Murshudov, How good are my data and what is the resolution? Acta Crystallogr. D Biol. Crystallogr. 69 (2013) 1204-1214, https://doi.org/10. 1107/S0907444913000061.

[34] A.J. McCoy, R.W. Grosse-Kunstleve, P.D. Adams, M.D. Winn, L.C. Storoni, R.J. Read, Phaser crystallographic software, J. Appl. Crystallogr. 40 (2007) 658-674, https://doi.org/10.1107/S0021889807021206. 
[35] P.D. Adams, P.V. Afonine, G. Bunkóczi, V.B. Chen, I.W. Davis, N. Echols, J.J. Headd, L.-W. Hung, G.J. Kapral, R.W. Grosse-Kunstleve, A.J. McCoy, N.W. Moriarty, R. Oeffner, R.J. Read, D.C. Richardson, J.S. Richardson, T.C. Terwilliger, P.H. Zwart, PHENIX: a comprehensive Python-based system for macromolecular structure solution, Acta Crystallogr. D Biol. Crystallogr. 66 (2010) 213-221, https://doi.org/10.1107/S0907444909052925.

[36] P. Emsley, B. Lohkamp, W.G. Scott, K. Cowtan, Features and development of Coot, Acta Crystallogr. D Biol. Crystallogr. 66 (2010) 486-501, https://doi.org/10.1107/ S0907444910007493.

[37] The PyMOL Molecular Graphics System, Version 2.0 Schrödinger, LLC, (2015).

[38] W. Humphrey, A. Dalke, K. Schulten, VMD: visual molecular dynamics, J. Mol. Graph. 14 (1996) 33-38, https://doi.org/10.1016/0263-7855(96)00018-5.

[39] M. de Rosa, A. Barbiroli, S. Giorgetti, P.P. Mangione, M. Bolognesi, S. Ricagno, Decoding the structural bases of D76N ß2-microglobulin high amyloidogenicity through crystallography and Asn-scan mutagenesis, PLoS One 10 (2015) e0144061, , https://doi.org/10.1371/journal.pone.0144061.

[40] S. Doerr, M.J. Harvey, F. Noé, G. De Fabritiis, HTMD: high-throughput molecular dynamics for molecular discovery, J. Chem. Theory Comput. 12 (2016) 1845-1852, https://doi.org/10.1021/acs.jctc.6b00049.

[41] G. Martínez-Rosell, T. Giorgino, G. De Fabritiis, PlayMolecule ProteinPrepare: a web application for protein preparation for molecular dynamics simulations, J. Chem. Inf. Model. 57 (2017) 1511-1516, https://doi.org/10.1021/acs.jcim. $7 \mathrm{~b} 00190$.

[42] R.B. Best, X. Zhu, J. Shim, P.E.M. Lopes, J. Mittal, M. Feig, A.D. Mackerell Jr., Optimization of the additive CHARMM all-atom protein force field targeting improved sampling of the backbone $\varphi, \psi$ and side-chain $\chi(1)$ and $\chi(2)$ dihedral angles, J. Chem. Theory Comput. 8 (2012) 3257-3273, https://doi.org/10.1021/ ct300400x.

[43] M.J. Harvey, G. Giupponi, G.D. Fabritiis, ACEMD: accelerating biomolecular dynamics in the microsecond time scale, J. Chem. Theory Comput. 5 (2009) 1632-1639, https://doi.org/10.1021/ct9000685.

[44] M. Necci, D. Piovesan, Z. Dosztányi, S.C.E. Tosatto, A. Valencia, MobiDB-lite: fast and highly specific consensus prediction of intrinsic disorder in proteins, Bioinformatics 33 (2017) 1402-1404, https://doi.org/10.1093/bioinformatics/ btx015.

[45] A.E. Eriksson, W.A. Baase, X.J. Zhang, D.W. Heinz, M. Blaber, E.P. Baldwin, B.W. Matthews, Response of a protein structure to cavity-creating mutations and its relation to the hydrophobic effect, Science 255 (1992) 178-183 https://www.ncbi. nlm.nih.gov/pubmed/1553543.

[46] H. Ashkenazy, S. Abadi, E. Martz, O. Chay, I. Mayrose, T. Pupko, N. Ben-Tal, ConSurf 2016: an improved methodology to estimate and visualize evolutionary conservation in macromolecules, Nucleic Acids Res. 44 (2016) W344-W350, https://doi.org/10.1093/nar/gkw408.

[47] B. Schneider, J.C. Gelly, A.G. de Brevern, J. Černý, Local dynamics of proteins and DNA evaluated from crystallographic B factors, Acta Crystallogr. D Biol. Crystallogr.
70 (2014) 2413-2419, https://doi.org/10.1107/S1399004714014631.

[48] L.J. Page, J.Y. Suk, L. Bazhenova, S.M. Fleming, M. Wood, Y. Jiang, L.T. Guo, A.P. Mizisin, R. Kisilevsky, G.D. Shelton, W.E. Balch, J.W. Kelly, Secretion of amyloidogenic gelsolin progressively compromises protein homeostasis leading to the intracellular aggregation of proteins, Proc. Natl. Acad. Sci. U. S. A. 106 (2009) 11125-11130, https://doi.org/10.1073/pnas.0811753106.

[49] G. Ratnaswamy, M.E. Huff, A.I. Su, S. Rion, J.W. Kelly, Destabilization of $\mathrm{Ca}^{2+}$-free gelsolin may not be responsible for proteolysis in Familial Amyloidosis of Finnish Type, Proc. Natl. Acad. Sci. U. S. A. 98 (2001) 2334-2339, https://doi.org/10. 1073/pnas.041452598.

[50] X. Pang, H.-X. Zhou, Disorder-to-order transition of an active-site loop mediates the allosteric activation of sortase A, Biophys. J. 109 (2015) 1706-1715, https://doi. org/10.1016/j.bpj.2015.08.039.

[51] K. Moritsugu, T. Terada, A. Kidera, Disorder-to-order transition of an intrinsically disordered region of sortase revealed by multiscale enhanced sampling, J. Am. Chem. Soc. 134 (2012) 7094-7101, https://doi.org/10.1021/ja3008402.

[52] D.P. O'Brien, S.E. Cannella, D. Durand, V.Y. Ntsogo Enguéné, B. Hernandez, M. Ghomi, O. Subrini, A. Hessel, C. Malosse, V. Hourdel, P. Vachette, J. ChamotRooke, S. Brier, D. Ladant, A. Chenal, Calcium tightly regulates disorder-to-order transitions involved in the secretion, folding and functions of the CyaA toxin of Bordetella pertussis, the causative agent of whooping cough, Biophys. J. 112 (2017) 523a, https://doi.org/10.1016/j.bpj.2016.11.2828.

[53] D.C. LaPorte, B.M. Wierman, D.R. Storm, Calcium-induced exposure of a hydrophobic surface on calmodulin, Biochemistry 19 (1980) 3814-3819, https://doi.org/ 10.1021/bi00557a025.

[54] B. Nagar, M. Overduin, M. Ikura, J.M. Rini, Structural basis of calcium-induced Ecadherin rigidification and dimerization, Nature 380 (1996) 360-364, https://doi. org/10.1038/380360a0.

[55] B. Dahl, F.V. Schiødt, P. Ott, R. Gvozdenovic, H.L. Yin, W.M. Lee, Plasma gelsolin is reduced in trauma patients, Shock 12 (1999) 102-104 https://www.ncbi.nlm.nih. gov/pubmed/10446889.

[56] J.A. Janovick, M.D. Stewart, D. Jacob, L.D. Martin, J.M. Deng, C.A. Stewart, Y. Wang, A. Cornea, L. Chavali, S. Lopez, S. Mitalipov, E. Kang, H.-S. Lee, P.R. Manna, D.M. Stocco, R.R. Behringer, P.M. Conn, Restoration of testis function in hypogonadotropic hypogonadal mice harboring a misfolded GnRHR mutant by pharmacoperone drug therapy, Proc. Natl. Acad. Sci. U. S. A. 110 (2013) 21030-21035, https://doi.org/10.1073/pnas.1315194110.

[57] A. Frustaci, C. Chimenti, R. Ricci, L. Natale, M.A. Russo, M. Pieroni, C.M. Eng, R.J. Desnick, Improvement in cardiac function in the cardiac variant of Fabry's disease with galactose-infusion therapy, N. Engl. J. Med. 345 (2001) 25-32, https://doi.org/10.1056/NEJM200107053450104.

[58] S.M. Johnson, S. Connelly, C. Fearns, E.T. Powers, J.W. Kelly, The transthyretin amyloidoses: from delineating the molecular mechanism of aggregation linked to pathology to a regulatory-agency-approved drug, J. Mol. Biol. 421 (2012) 185-203, https://doi.org/10.1016/j.jmb.2011.12.060. 